Review Article

\title{
Noncoding RNAs Carried by Extracellular Vesicles in Endocrine Diseases
}

\author{
Margherita A. C. Pomatto $\mathbb{D}^{1},{ }^{1}$ Chiara Gai $\mathbb{D}^{1},{ }^{1}$ Maria Chiara Deregibus $\mathbb{D}^{1,2}$ Ciro Tetta, ${ }^{3}$ \\ and Giovanni Camussi (iD) \\ ${ }^{1}$ Stem Cell Laboratory, Department of Medical Sciences, University of Turin, Turin, Italy \\ ${ }^{2} 2$ i3T Scarl, Univerity of Turin, Turin, Italy \\ ${ }^{3}$ Unicyte AG, Oberdorf, Nidwalden, Switzerland
}

Correspondence should be addressed to Giovanni Camussi; giovanni.camussi@unito.it

Received 22 November 2017; Accepted 16 January 2018; Published 1 April 2018

Academic Editor: Claudiane Guay

Copyright (c) 2018 Margherita A. C. Pomatto et al. This is an open access article distributed under the Creative Commons Attribution License, which permits unrestricted use, distribution, and reproduction in any medium, provided the original work is properly cited.

\begin{abstract}
RNA molecules are essential and fine regulators of important biological processes. Their role is well documented also in the endocrine system, both in physiological and pathological conditions. Increasing interest is arising about the function and the importance of noncoding RNAs shuttled by extracellular vesicles (EVs). In fact, EV membrane protects nucleic acids from enzyme degradation. Nowadays, the research on EVs and their cargoes, as well as their biological functions, faces the lack of standardization in EV purification. Here, the main techniques for EV isolation are discussed and compared for their advantages and vulnerabilities. Despite the possible discrepancy due to methodological variability, EVs and their RNA content are reported to be key mediators of intercellular communication in pathologies of main endocrine organs, including the pancreas, thyroid, and reproductive system. In particular, the present work describes the role of RNAs contained in EVs in pathogenesis and progression of several metabolic dysfunctions, including obesity and diabetes, and their related manifestations. Their importance in the establishment and progression of thyroid autoimmunity disorders and complicated pregnancy is also discussed. Preliminary studies highlight the attractive possibility to use RNAs contained in EVs as biomarkers suggesting their exploitation for new diagnostic approaches in endocrinology.
\end{abstract}

\section{Introduction}

The larger fraction of transcribed RNAs is composed by noncoding RNAs, instead of mRNAs coding for proteins [1]. Noncoding RNAs include a wide variety of RNA molecules, such as transfer RNAs (tRNAs), ribosomal RNAs (rRNAs), small nuclear RNAs (snRNAs), circular RNAs (cRNAs), and small nucleolar RNAs (snoRNAs) with several different regulatory and structural functions. They are involved in mRNA translation and splicing, transcription initiation, but also cell cycle regulation, chromosome maintenance and segregation, chromatin remodeling, and epigenetic memory regulation [1]. Noncoding RNAs also include cytoplasmic Y RNAs (yRNAs) and vault RNAs (vtRNAs). YRNAs are involved in chromosomal DNA replication and in RNA stability when complexed with
Ro60 ribonucleoprotein particle. YRNAs also modulate cell death and inflammation $[2,3]$. VtRNAs are a part of large ribonucleoprotein particles present in the cytoplasm of many eukaryotic cells, which are suggested to be involved in several processes, including multidrug resistance of cancer cells, DNA damage repair, innate immune response, apoptosis resistance, nuclear pore complex formation, and nucleocytoplasmic transport $[4,5]$. However, their functions are still not completely elucidated. Two other well-studied classes of noncoding RNAs are microRNAs (miRNAs) and small interference RNA (siRNAs), short single-strand RNA molecules (20-22 nucleotides) derived from hairpin or doublestranded RNA precursors. These RNAs are loaded by the Dicer complex into a member of the Argonaute protein subfamily to form the RNA-induced silencing (RISC) complex, which recognizes a complementary sequence in the 
target mRNA and mediates degradation or inhibits translation into protein [6]. miRNAs regulate posttranscriptional gene silencing of up to $60 \%$ of protein-coding genes targeting one or several mRNAs. They have been associated to quite all biological processes, including development, proliferation, differentiation, metabolism, apoptosis, and cancer [7]. Finally, a large part of the mammalian noncoding transcripts is composed by long noncoding RNAs (lncRNAs), RNA molecules of approximately 200 nucleotides or more. LncRNAs take part in several biological processes: they regulate transcription by affecting the activity of specific transcription factors and polymerases. They mediate posttranscriptional regulation, by influencing splicing, transport, translation, and degradation of mRNAs, and they take part in epigenetic modifications, by regulating chromatin remodeling and $\mathrm{X}$ chromosome inactivation in mammals $[8,9]$. Interestingly, lncRNAs can also modulate the biological activity of other RNA species. LncRNAs can interact with miRNAs and inhibit their effect by acting as "competing endogenous RNAs" (ceRNAs). LncRNAs containing miRNA-binding sequence regions can impound miRNA molecules and reduce their availability for target mRNAs [10]. This mechanism of interaction has been recently demonstrated to play a critical role in several pathological processes, including cancers [11-13], fat deposition [14], diabetic retinopathy [10], and osteoarthritis [15], and in biological processes such as cellular apoptosis [16-18] and stem cell differentiation [19].

During the last few years, extracellular vesicles (EVs) have been recognized as carriers of RNA molecules from their cell of origin to recipient cells all over the organism. Indeed, EVs are a heterogeneous class of vesicles ranging from 20 to $1000 \mathrm{~nm}$, delimited by plasma membrane (PM) and containing proteins and nucleic acids. In this review, we will collectively refer to EVs that include several subpopulations, such as microvesicles, microparticles, and exosomes, basing on their size, biogenesis, molecular markers, and isolation techniques $[20,21]$.

\section{EVs and Communication}

It is now clear that EVs play an important role in cell to cell communication between neighboring and distant cells. In fact, EVs are released by quite all cell types and have been detected in several biological fluids [22]. Recipient cells uptake EVs by receptor-mediated interactions or by direct fusion with the PM [23]. In this way, EVs transfer lipids, membrane receptors, proteins, or nucleic acids to recipient cells. First evidence that EVs mediate the horizontal transfer of proteins and mRNAs and reprogram recipient cells was provided by Ratajczak et al. [24]. Recently, some interesting in vivo studies have used Cre recombinase technique [25-27] or a combination of fluorescent and bioluminescent reporters tagging EV membrane and RNA molecules [28] to demonstrate that mRNAs are transferred from cell to cell by EVs. Being mediators of cell to cell interaction, EVs play a complex role in pathophysiology of several organs and diseases. The biological effects of EVs depend on their origin, on the status, and on the environment. Stem cell-derived EVs elicit, at least in part, the regenerative properties of their cell of origin. Particularly, EVs released by mesenchymal stromal cells (MSCs) have been widely studied and showed immunomodulatory properties and a protective role in cardiovascular disease, kidney disease, lung disease, and liver disease [29]. MSC-derived EVs exploit both antitumor and protumorigenic activity based on the context [30]. On the other hand, EVs released by cancer stem cells, such as renal cancer stem cells [31] or prostate cancer stem cells [32], can promote tumor metastasis. In general, EVs act influencing different biological processes and tumor-derived EVs can support tumor in several ways, by promoting cell migration, invasiveness, angiogenesis, and premetastatic niche formation in distant sites [33]. EVs from different other cells, adipose mesenchymal stem cells (ASCs), endothelial cells, proangiogenic progenitors, and tumor cells, show proangiogenic properties in vitro and in vivo, in ischemic injury or in tumors [34].

\section{EV Biogenesis and Cargo}

EVs can be classified into two different groups based on their biogenesis: microvesicles and exosomes. Microvesicles originate by shedding from the cell surface. Changes in the composition of lipids, proteins, and other components of the PM modify the curvature of the membrane and facilitate the microvesicle budding. This process relies, in part, on the interaction of proteins such as arrestin domain-containing protein-1 (ARRDC1) with the late endosomal protein TSG101. Microvesicle fission is due to myosin and actin cytoskeletal rearrangements regulated by the Ras-related GTPase ADP-ribosylation factor 6 (ARF6) and its signaling cascade [35]. Exosomes are formed by budding of the membrane into the lumen of multivesicular bodies (MVB), which are part of the endocytic pathway and fuse with the PM releasing exosomes outside the cell. Several proteins are involved with the formation of exosomes, such as the components of the endosomal sorting complex required for transport (ESCRT) machinery and the accessory proteins TSG101, ALIX, and VPS4. However, other ESCRTindependent mechanisms have been described [36]. The docking of MVB with the PM is mediated by several components of the RAB family of small GTPase proteins (RAB2B, RAB5A, RAB7, RAB9A, RAB11, RAB27A, RAB27B, RAB35 [37], and RLP-1 [38]). Some members of the tetraspanin family, such as CD63, CD81, and CD9, are enriched in exosomes and have been recognized as exosome markers [37]. On the other hand, specific markers for microvesicles are lacking and it is difficult to discriminate EVs based on biomarkers. Moreover, even if the biogenesis of microvesicles and exosomes is based on different processes, some mechanisms are shared [36].

EV content varies depending on the originating cell and the biogenesis mechanism. However, the compartmentalization of proteins and RNAs is, at least in part, a regulated process. Comparative lipidomic, proteomic, and transcriptomic analysis usually finds an enrichment of subsets of lipids, proteins, or RNAs in EVs compared with their cells of origin [39-43]. Several proteins involved in EV biogenesis regulate compartmentalization into EVs. For example, ESCRT complex recruits proteins into both exosomes and 
microvesicles [44]. In human liver stem cells, ALIX is associated with Ago2, a member of the Argonaute protein family, which binds miRNAs. The complex ALIX-Ago2miRNA was found in EVs [45]. In breast cancer, EVs contain functional Ago2-associated miRNAs, which are mature and induce transcriptome alterations in target cells [46]. The heterogeneous nuclear ribonucleoprotein A2B1 (hnRNPA2B1) recognizes specific motifs and regulates miRNA loading into EVs [47]. The RNA-binding protein Y-box protein I (YBX1) binds to miR-223 and is necessary for its packaging into EVs [48]. In colorectal cancer cells, KRAS seems to mediate miRNA sorting into EVs [49] by regulating Ago2 secretion [50]. Besides miRNAs, increasing reports show that EVs are particularly enriched in other types of small RNAs, such as tRNA fragments, yRNAs, vtRNAs, and miRNA fragments [51-53]. The presence of a regulated mechanism of small RNA sorting into EVs has been observed also in Leishmania, suggesting that it is conserved throughout evolution [54]. However, the biological functions of small RNAs found in EVs are not completely clear.

\section{Techniques for EV Isolation}

Before addressing the main topic of this review relative to the role of noncoding RNA shuttled by EVs in endocrine pathophysiology, it is useful to discuss the technical challenges in EV purification as these may influence the analysis of RNAs contained in EVs [55]. In fact, EVs are heterogeneous in size and molecular composition (membrane lipids, surface proteins, and cargo), and thus in density and charge. The heterogeneity is increased as EVs derive from different cell of origin (e.g., biological fluids such as blood or saliva). This is a relevant problem since the purity, the integrity, the yield, and the biological activity of EVs are influenced by the isolation technique $[56,57]$. Each isolation technique presents advantages and disadvantages, and the choice of the methods should be based on the starting material and volume, on the grade of purity desired, and on the purpose of the isolation (research, therapeutic, or diagnostic use).

The standard technique is differential ultracentrifugation. This protocol is based on several consecutive centrifugation steps. First steps are necessary to discard cells and debris and consist in brief centrifugation at low centrifugal forces (g). The consecutive steps isolate different populations of EVs based on density (i.e., 10,000 $\mathrm{g}$ for microvesicles and $100,000 \mathrm{~g}$ for exosomes). The protocol was firstly described by Raposo et al. [58] and then widely adopted with slight variations depending on the source of EVs (cell supernatant or biological fluids) $[59,60]$. It is often combined with other techniques, mostly the density gradient with or without cushion, to stratify EVs based on their density and obtain a pure population, free of contaminant proteins, especially to perform proteomic or other molecular analysis [61-64]. Iodixanol (OptiPrep), rather than sucrose, is preferred for gradient because it reduces contaminants such as HDL $[65,66]$, small apoptotic bodies, and virus [67]. Recently, an upward floating method into iodixanol gradient has been proposed by Kowal et al. [68] to better separate and to characterize subtypes of EVs. Some concerns exist over the possibility that high-speed centrifugation may damage EVs and create aggregates [69]. Another issue is related to the low reproducibility of the technique. Adopting different rotors, speeds, and times, yield, protein, and RNA content of the pellet might vary [70]. Nevertheless, differential ultracentrifugation is still the most widely used method, especially for conditioned cell culture media [64].

Another technique is size-exclusion chromatography (SEC). EVs flow into a filtration column that elutes EVs of different sizes in different fractions. This method is preceded by a preconcentration step and followed by ultracentrifugation that can damage EVs [71]. In other cases, SEC is used as a stand-alone technique [72, 73]. It seems that SEC is preferentially used to isolate EVs from complex biological fluids, such as plasma [74, 75], urine [76], and milk [73]. Two studies comparing ultracentrifugation and SEC suggest that SEC provides a higher yield of EVs [77] and contaminant reduction [78]. Other size-based isolation methods are ultrafiltration, flow field-flow fractionation, hydrostatic filtration dialysis [79], an integrated double-filtration microfluidic device [80], and lab-on-a-disc integrated with two nanofilter devices [81].

Moreover, EVs can be isolated with immunoaffinity capture-based techniques, which use microbeads coated with antibodies for EV membrane receptors to recognize and isolate EVs. This approach selects specific subpopulations of EVs without considering their size or density [71]. Therefore, this method may be unsuitable for some application, but it is very useful for others, such as the detection of diagnostic or prognostic markers expressed on EV surfaces. Moreover, this method can be coupled to flow cytometry, Western blotting, and real-time PCR to furtherly characterize EVs [71]. The same method has been used to develop an ELISA microplate for the capture and quantification of EVs from urine, serum, and plasma [82]. Besides, immunoaffinity isolation is more used for complex biological fluids than for cell supernatants, or with small starting volumes [64].

Another method of EV isolation is based on precipitation. Polymers such as polyethylene glycol (PEG), which separate water from solutes, are incubated overnight at $4^{\circ} \mathrm{C}$ with cell culture media or biological fluids, and EVs are collected by low-speed centrifugation or filtration [83]. Moreover, EV negative charge has been exploited to develop a charge-based precipitation method, which uses protamine, a positively charged molecule, coupled with PEG to separate EVs [84]. Precipitation techniques recover EVs more efficiently than ultracentrifugation $[84,85]$. Moreover, precipitation techniques require very small volumes and are easier to perform. For this reason, this technique is suitable for diagnostic use. On the other hand, it is possible to coprecipitate contaminants, such as lipoproteins and the polymer itself [86]. However, these particles can be removed by a preisolation centrifugation and a post isolation filtration through Sephadex G-25 spin columns [57, 84].

\section{Metabolic Syndrome}

In the last years, it has been suggested that miRNAs, both intracellular and extracellular, can control the metabolic 
TABLE 1: EV-miRNA molecules in endocrine diseases.

\begin{tabular}{|c|c|c|c|c|c|c|}
\hline Pathology & EV source & $\begin{array}{l}\text { miRNA } \\
\text { alteration }\end{array}$ & Target & Recipient cell & Activity & Reference \\
\hline $\begin{array}{l}\text { Metabolic } \\
\text { syndrome }\end{array}$ & $\begin{array}{l}\text { Macrophages of adipose } \\
\text { tissue of obese mice }\end{array}$ & $\uparrow \mathrm{miR}-155$ & $\operatorname{PPAR} \gamma$ & $\begin{array}{c}\text { Liver and } \\
\text { muscle cells }\end{array}$ & $\begin{array}{l}\text { Glucose metabolism, insulin } \\
\text { sensitivity }\end{array}$ & {$[103]$} \\
\hline \multirow{2}{*}{ Obesity } & Obese visceral adipocytes & $\begin{array}{c}\downarrow \mathrm{miR}-148 \mathrm{~b} \\
\downarrow \text { miR-4269 } \\
\uparrow \mathrm{miR}-23 \mathrm{~b} \\
\uparrow \mathrm{miR}-4429\end{array}$ & $\begin{array}{c}\text { TGF- } \beta \\
\text { Wnt } / \beta \text {-catenin }\end{array}$ & - & Involvement in liver diseases & {$[107]$} \\
\hline & $\begin{array}{l}\text { White and mostly brown } \\
\text { adipocytes }\end{array}$ & $\begin{array}{c}\text { miR-99b } \\
\text { miR-325 } \\
\text { miR-743b } \\
\text { miR-98 }\end{array}$ & $\begin{array}{l}\text { FGF21 } \\
\text { UCP1 } \\
\text { PGCI } \alpha\end{array}$ & Liver cells & $\begin{array}{l}\text { Metabolic injury (glucose } \\
\text { metabolism injury) }\end{array}$ & [109] \\
\hline \multirow[t]{2}{*}{ Liver } & ASCs of obese subjects & $\downarrow \mathrm{miR}-126$ & $\begin{array}{c}\uparrow \text { Spred1 } \\
\uparrow \mathrm{E} 2 \mathrm{~K} 1 / 2 \\
\mathrm{MAPK}\end{array}$ & - & $\begin{array}{l}\text { Reduced EC migration and } \\
\text { angiogenesis }\end{array}$ & {$[111]$} \\
\hline & NAFLD mouse model & $\begin{array}{l}\uparrow \operatorname{miR}-122 \\
\uparrow \operatorname{miR}-192\end{array}$ & - & - & $\begin{array}{l}\text { EVs as potential biomarkers of } \\
\text { hepatic injury }\end{array}$ & {$[125]$} \\
\hline \multirow[t]{3}{*}{ Pancreas } & Human pancreatic islets & $\begin{array}{l}\text { miR-27b } \\
\text { miR-126 } \\
\text { miR-130 } \\
\text { miR-296 }\end{array}$ & - & $\begin{array}{l}\text { Human islet } \\
\text { ECs }\end{array}$ & $\begin{array}{l}\text { Beta cell function, insulin } \\
\text { secretion, angiogenesis }\end{array}$ & {$[131]$} \\
\hline & EPCs & $\begin{array}{l}\text { miR-126 } \\
\text { miR-296 }\end{array}$ & - & $\begin{array}{l}\text { Human islet } \\
\text { ECs }\end{array}$ & $\begin{array}{c}\text { Angiogenesis promotion in vitro } \\
\text { and in vivo }\end{array}$ & {$[132]$} \\
\hline & Skeletal muscle & $\operatorname{miR}-16$ & Ptch1 & $\begin{array}{l}\text { Pancreatic beta } \\
\text { cells }\end{array}$ & $\begin{array}{l}\text { Development of insulin } \\
\text { resistance }\end{array}$ & {$[142]$} \\
\hline \multirow[t]{2}{*}{ Diabetes } & $\begin{array}{l}\text { Urine of patients with } \\
\text { diabetic nephropathy }\end{array}$ & $\begin{array}{l}\uparrow \mathrm{miR}-130 \mathrm{a} \\
\uparrow \mathrm{miR}-145 \\
\downarrow \mathrm{miR}-155 \\
\downarrow \mathrm{miR}-424\end{array}$ & - & - & $\begin{array}{l}\text { Involvement in diabetes } \\
\text { progression }\end{array}$ & {$[152]$} \\
\hline & ECs & $\begin{array}{l}\text { miR-143/ } \\
\text { miR-145 cluster }\end{array}$ & - & $\begin{array}{c}\text { Vascular } \\
\text { smooth muscle } \\
\text { cells }\end{array}$ & Endothelium stabilization & {$[164]$} \\
\hline \multirow[b]{2}{*}{$\begin{array}{l}\text { Thyroid } \\
\text { disorders }\end{array}$} & AITD patients & $\begin{array}{l}\uparrow \mathrm{miR}-146 \mathrm{a} \\
\uparrow \mathrm{miR}-155\end{array}$ & SMAD4 & - & $\begin{array}{l}\text { Function and development of } \\
\text { Treg and Th17 cells }\end{array}$ & {$[176]$} \\
\hline & Intractable Graves' disease & $\begin{array}{c}\text { miR-92a-3p } \\
\text { miR-23b-5p } \\
\text { miR-339-5p } \\
\text { let7g-3p }\end{array}$ & - & - & $\begin{array}{l}\text { Potential role in upregulation of } \\
\text { cytokine production }\end{array}$ & {$[181]$} \\
\hline \multirow[t]{2}{*}{ Preeclampsia } & $\mathrm{STB}$ in in vitro model of $\mathrm{PE}$ & $\begin{array}{c}\downarrow \mathrm{miR}-517 \mathrm{a} \\
\downarrow \mathrm{miR}-517 \mathrm{~b} \\
\downarrow \mathrm{miR}-141\end{array}$ & - & - & - & [213] \\
\hline & PE patients & $\begin{array}{l}\uparrow \mathrm{miR}-486-1-5 \mathrm{p} \\
\uparrow \mathrm{miR}-486-2-5 \mathrm{p}\end{array}$ & - & - & Potential PE biomarkers & {$[214]$} \\
\hline
\end{tabular}

EV: extracellular vesicle; PPAR $\gamma$ : peroxisome proliferator-activated receptor gamma; TGF- $\beta$ : transforming growth factor beta; FGF21: fibroblast growth factor-21; UCP1: uncoupling protein 1; PGCI $\alpha$ : peroxisome proliferator-activated receptor gamma coactivator 1-alpha; ASCs: adipose mesenchymal stem cells; Spred1: sprouty-related EVH1 domain-containing 1; E2K1/2 MAPK: extracellular signal-regulated kinase 1/2 mitogen-activated protein kinase; EC: endothelial cell; NAFLD: nonalcoholic fatty liver disease; EPCs: endothelial progenitor cells; Ptch1: protein patched homolog 1; AITD: autoimmune thyroid disease; SMAD4: SMAD family member 4; Treg: T regulatory cells; Th17: T helper 17 cells; STB: syncytiotrophoblast; PE: preeclampsia. Expression trend: $\uparrow:$ miRNA increased expression; $\downarrow$ : miRNA reduced expression.

homeostasis and may impact the main tissues involved in the development of the metabolic syndrome [87]. In effect, miRNAs represent important modulators of glucose and lipid metabolism in the liver [88], insulin production in the pancreas [89], and leptin signaling in the hypothalamus [90]. In addition, miRNAs have been involved in many processes associated to metabolic disorders such as oxidative stress, inflammation, insulin signaling, adipogenesis, and angiogenesis. In this part, we describe the recent knowledge on the role of RNAs shuttled by EVs in metabolic syndrome and correlated disorders. Most relevant EV-cargoes involved in endocrine diseases discussed here and in the following paragraphs are summarized in Table 1. 
5.1. Obesity. Obesity is a chronic condition characterized by an excessive accumulation of body fat potentially associated to other metabolic disorders, hypertension, insulin resistance, and cardiovascular diseases. Human obesity associates with a chronic state of low-grade inflammation with augmentation of inflammatory protein production, increased infiltration of macrophages, lipolytic activity of adipocytes with increased systemic liberation of fatty acids, and potential insulin resistance. The increased production of proinflammatory cytokines and the decrease of antiinflammatory cytokines may take part in the metabolic complications linked with obesity and leading to metabolic syndrome. This condition is modulated by signal transduction networks, and miRNAs may regulate the expression and production of inflammatory proteins with amplification of the inflammatory effect [91]. Adipose tissue is a heterogeneous tissue composed by several cell types. Adipocytes and ASCs for instance may release EVs that regulate adipocyte metabolism. In effect, when the adipose-specific knockout of Dicer is performed, a depletion of most miRNAs is observed [92-94]. miRNA deficit prejudices adipocyte basic functions like differentiation, metabolism, and signaling [94]. It has been shown that several miRNAs may contribute to the infiltration of macrophages in the adipose tissue [95-97] and to their transition to a proinflammatory phenotype [98-101] favoring the low-grade chronic inflammation characteristic of obese people and the induction of insulin resistance [102].

A recent work by Ying et al. [103] showed that adipose tissue macrophages may regulate systemic insulin responses via EVs. The authors reported that macrophages from adipose tissue of obese mice released EVs carrying miRNAs able to induce insulin resistance and glucose intolerance in lean mice. At variance, EVs from adipose tissue macrophages of lean mice were able to ameliorate glucose metabolism and insulin sensitivity of obese mice. MiR-155, targeting the peroxisome proliferator-activated receptor gamma (PPAR $\gamma$ ) gene, was upregulated in EVs of obese adipose tissue macrophages. EV-mediated transfer of miR-155 to insulin target cells of the liver and muscle may have an impact on metabolism [103]. In humans, PPAR $\gamma$ exerts several important functions in adipocyte differentiation, lipid metabolism, and glucose homeostasis [104]. As a matter of fact, some studies have outlined that EVs released from adipose tissue may take part in the metabolic features associated with obesity [105-107] and differ from those of lean individuals $[107,108]$.

The potential benefits of EVs for biomarker identification are related to their easy purification, their stability when stored at $-80^{\circ} \mathrm{C}$, the protection of nucleic acids from enzyme degradation, and the possibility of EV subset discrimination based on the expression of membrane markers of the cell of origin. Karolina et al. [108] analyzed the profile of miRNAs in EVs of patients with metabolic syndrome, hypercholesterolemia, hypertension, or type 2 diabetes mellitus alone, showing a distinct miRNA profile for each single disease. Ferrante et al. [107] demonstrated a different expression of several miRNAs in obese in respect to lean visceral adipocyte EVs. In particular, downregulation of miR-148b and
miR-4269 and upregulation of miR-23b and miR-4429 were reported in obese visceral adipocyte EVs. These altered miRNAs targeted the TGF- $\beta$ and Wnt $/ \beta$-catenin signaling linked to the modulation of chronic inflammation and adipogenic differentiation of ASCs [107]. It has been shown that EVs from adipose tissue intravenously injected in an obese mouse model (B6 ob/ob mice) or in mice fed with a high-fat diet were incorporated in peripheral blood monocytes following macrophage activation in a TLR4-dependent way. This led to increased secretion of TNF- $\alpha$ and interleukin- 6 and development of insulin resistance [105]. Recently, Thomou et al. [109] demonstrated that the adipose tissue is a great source of circulating vesicular miRNAs capable of modulating gene expression in other tissues. The authors showed that circulating vesicular miRNAs are decreased in mice with a fatspecific knockout of Dicer, and in humans with lipodystrophy. The transplantation of white adipose tissue and mostly of brown adipose tissue into Dicer knockout mice was followed by restoration of circulating vesicular miRNAs, amelioration of glucose tolerance, and reduction of fibroblast growth factor-21 (FGF21) mRNA in the liver and of protein in blood [109]. FGF-21 is a hormone that is induced in the liver by fasting [110] and was repressed when liver cells were incubated with normal serum EVs but not with Dicer knockout EVs [108]. In EVs from Dicer knockout mice, the effect was restored by introduction of miR-99b, a predicted regulator of mouse FGF21. Moreover, the authors demonstrated that transplantation of brown adipose tissue reestablished other miRNAs such as miR-325 and miR-743b, predicted to target the uncoupling protein 1 (UCP-1, an uncoupling protein found in the mitochondria of brown adipose tissue), and miR-98 predicted to target the peroxisome proliferatoractivated receptor gamma coactivator 1-alpha (PGCI $\alpha)$, the master regulator of mitochondrial biogenesis. Taken together, these data suggest that miRNAs carried by EVs could be transferred to other tissues where they are able to modulate gene expression [109]. It has been shown that ASCs release EVs capable of promoting endothelial cell migration, proliferation, and neoangiogenesis [111]. In obese subjects, the ASC-EV angiogenic potential resulted weakened in comparison with normal individuals with reduced endothelial cell migration and vessel-like structure formation [112]. This effect was mainly due to a reduced miR-126 content in EVs leading to Spred1 upregulation and inhibition of the extracellular signal-regulated kinase $1 / 2$ mitogen-activated protein kinase (Erk1/2 MAPK) pathway in endothelial cells. Moreover, the treatment of nonobese ASCs with palmitic acid induced the release of EVs similar to those from obese, whereas the treatment of obese ASCs with high glucose decreased the miR-126 content in EVs and the in vitro angiogenesis [112].

Beside miRNAs, EVs were shown to contain lncRNAs [113]. Little is known on the role of lncRNAs carried by EVs in endocrine physiology and pathology. However, it has been reported that lncRNAs exert critical roles in homeostasis and differentiation of metabolic tissues interacting with target mRNAs or miRNAs $[114,115]$.

To date, accumulating evidence supports an association of diabetes and metabolic syndrome to liver disease 
[116, 117]. Like EVs released by adipose tissue, EVs produced by hepatocytes are sensitive to metabolic signals, but their importance in the interplay between metabolically active tissues and the liver is still uncertain [118]. It has been suggested that EVs carrying miRNAs released from different hepatic cells are involved in liver functions and play a role in liver diseases [119, 120].

Obesity and metabolic syndrome may enable the accumulation of fat in the hepatic tissues with the development of nonalcoholic fatty liver disease (NAFLD) [121]. It can initiate as simple steatosis, then advance to nonalcoholic steatohepatitis (NASH) in which inflammation and fibrosis associate to steatosis, eventually leading to cirrhosis [122]. It has been shown that macrophages and natural killer $\mathrm{T}$ cells of subjects suffering NAFLD or NASH release a higher amount of EVs in the circulation, in respect to healthy individuals [123]. Since their release correlated with alanine aminotransferase (ALT) levels and the degree of histologic damage, EVs have been suggested as a new noninvasive and quantitative diagnostic tool [123]. Povero et al. [124], in a NASH in vitro model of lipotoxicity, demonstrated that hepatocytes released EVs with proangiogenic activity on endothelial cells. This process was dependent on the EV membrane expression of the protein vanin-1, which mediated EV internalization in target cells and subsequent caspase 3 activation. Therefore, hepatocyte-derived vanin-1-positive EVs have been suggested as potential biomarker or target for therapy of NASH [124]. Moreover, the same authors showed that the quantity of liver and blood EVs was markedly increased in a choline-deficient L-amino acid (CDAA) diet experimental model of NAFLD in comparison with control mice [125]. The number of EVs increased over time and correlated with the degree of histopathological lesions. Interestingly, these circulating EVs showed a different pattern of proteins and an enrichment of two wellknown miRNAs highly expressed in hepatocytes, miR-122 and miR-192. These results suggest a potential use of these EVs as biomarkers of hepatic damage [125]. Hirsova et al. [126] showed that toxic lipids, such as palmitate and its active metabolite lysophosphatidylcholine, induced an increased release of EVs from human hepatocytes. This process was mediated by the activation of the death receptor 5 signaling pathway in hepatocytes with downstream activation of caspases and of Rho-associated coiled-coil containing protein kinase 1 (ROCK1) [126]. These EVs carried the protein tumor necrosis factor-related apoptosis-inducing ligand (TRAIL) and could represent a possible connection between liver lipotoxicity and macrophage-mediated inflammation in NASH. In fact, the treatment with the ROCK1 inhibitor fasudil decreased the number of total and hepatocytederived circulating EVs in an in vivo model of NASH. Importantly, it induced a reduction of inflammation, hepatic damage, and fibrosis, suggesting the role of EVs in these mechanisms [126]. Moreover, Koeck et al. [127] isolated EVs from visceral adipose tissue of obese and lean patients and investigated their effects on cultured hepatic cell lines. Interestingly, incubation of liver cells with EVs from obese subjects dysregulated the TGF- $\beta$ pathway, a process correlated with the pathogenesis of NAFLD [127]. As mentioned above, Ferrante et al. [107] demonstrated that EVs derived from obese subjects carry miRNAs which interfere with TGF- $\beta$ pathway, suggesting their involvement in liver diseases. A recent study of Thomou and colleagues demonstrates that EVs derived from adipose tissue can guide metabolic insults in the liver via the transfer of miRNAs [109].

\subsection{Diabetes}

5.2.1. EVs in Endocrine Pancreas Physiology. Pancreatic beta cells, situated within the islets of Langerhans, are crucial for the regulation of blood glucose homeostasis by secreting insulin. Several evidences demonstrated that noncoding RNAs control beta cell function and viability in health and disease [128]. Recently, it has been demonstrated that these cells release EVs involved in signal interactions influencing the activity of adjacent pancreatic beta cells. In fact, EVs isolated from beta cell lines and from rat, mice, or human islets contained miRNAs that can be transferred to neighboring beta cells, influencing their behavior. Importantly, EVmiRNA content varies based on cell conditions and EVs released by beta cells treated with proinflammatory cytokines were shown to lead to apoptosis of naive beta cells [129]. Besides the direct interaction between beta cells, the physiopathology of pancreatic islets has been demonstrated to depend on a crosstalk between beta cells and endothelial cells [130]. EVs seem to contribute to cell communication, and EVs isolated from human pancreatic islets were shown to be biologically active, inducing insulin mRNA expression, enhancement of angiogenesis, and protection from apoptosis. In fact, these EVs shuttle specific mRNAs and miRNAs into target human islet endothelial cells, including several mRNAs (VEGFa, eNOS) and microRNAs (miR-27b, miR126, miR-130, and miR-296) involved in beta cell function, insulin secretion, and angiogenesis [131]. Moreover, EVs derived from endothelial progenitor cells (EPCs) induce in vitro islet endothelial cell migration, proliferation, organization in vessel-like structures, and resistance to apoptosis. In vivo, EVs were shown to favor survival, insulin secretion, and revascularization of islets transplanted in SCID mice. Of note, their effect is due to the transfer of proangiogenic miRNAs, miR-126 and miR-296 [132].

5.2.2. EVs in Diabetes. Insufficient and/or ineffective insulin secretion or both of them can lead to diabetes mellitus (DM). The autoimmune beta cell destruction in the pancreas is the cause of insulin-dependent type 1 diabetes (T1D), whereas insulin resistance (IR) or inadequate insulin release is the cause of non-insulin-dependent diabetes (T2D). A potential involvement of miRNAs in the dialogue between immune system and pancreatic islets has been suggested [133]. A recent study [134] has suggested that EVs may take part in the beginning and acceleration of autoimmune pancreatic islet reactions in T1D demonstrating that rat and human pancreatic beta cells secrete EVs carrying autoantigens GAD65, IA-2, and insulin/proinsulin which target and activate dendritic cells promoting autoimmunity in particular under proinflammatory conditions. Evidence indicates the crucial role of miRNAs in the beta cell differentiation, 
acquirement of a mature phenotype, and dysfunction. In effect, the pancreatic-specific deletion in mouse embryos of Dicer was followed by a dramatic deficiency of insulin producing beta cells linked to upregulation of the notchsignaling target Hes1 and decrease in the formation of endocrine progenitor cells expressing the neurogenin3 gene [135].

In DM, miRNAs can regulate various molecular and cellular pathways like insulin synthesis and secretion in pancreatic beta cells, exocytosis of insulin granules, beta cell fate, and formation of islets [136]. Many miRNAs contribute to the adaptive features of beta cells to increase requirements of insulin such as miR-132 [137, 138], miR-184 [139], miR-338-3p [140], and miR-375 [141, 142].

EVs regulate intercellular signaling in diabetes mediating the exchange of RNAs between cells. Recently, miRNAs delivered by EVs have been demonstrated to mediate the crosstalk between skeletal muscle and beta cells in diabetes [143]. This study used mice fed with a high palmitate diet inducing hyperglycemia, glucose intolerance, hyperinsulinaemia, and insulin resistance. Interestingly, EVs isolated from skeletal muscle can be internalized by pancreatic beta cells with delivering of proteins and miRNAs, suggesting that they contribute to modification of the beta cell mass arising during insulin resistance. In particular, lipidinduced insulin-resistant muscle EVs transferred miR-16 to beta cells regulating Ptch1, a receptor involved in the sonic hedgehog pathway and suggested to exert a significant role in insulin resistance development [143].

In addition to miRNAs, EVs can shuttle other noncoding RNAs, which regulate cell gene expression also interacting with miRNAs. In fact, recent studies have shown that EVs may carry and transfer cRNAs that may have functional and diagnostic relevance $[144,145]$. In particular, the human ciRS-7 (also termed Cdrlas) was detected in EVs [146] and is the first miRNA sponge identified, negatively regulating miR-7 [147]. Of note, a recent study underlined a critical relationship between ciRS-7/miR-7 and diabetes [148]. The authors demonstrated how the overexpression of Cdrlas augmented the insulin mRNA concentration and the granule secretion in beta cells via the inhibition of miR-7 in islet MIN6 cells and mouse islets [148]. In fact, miR-7 has been extensively related to diabetes impairing insulin secretion and beta cell dedifferentiation. Importantly, the knockdown of miR-7 in obese mice has been shown to ameliorate beta cell failure and glycemia [149]. Then, Cdrlas has been shown to improve beta cell function by preventing miR-7 interaction with its target genes. Among these, the authors demonstrated the importance of the paired box protein Pax-6 (Pax-6), which enhances insulin gene 1 (Ins1) and gene 2 (Ins2) transcripts by directly binding to their promoters increasing insulin content and secretion, and of Myrip (myosin VIIA and Rab-interacting protein), which forms a complex with Rab27a and MyosinVa and mediates insulin granule transportation and secretion [148]. These data suggest the presence of multiple types of vesicular RNAs involved in diabetes and highlight the necessity of further investigations to understand their complex role in this pathology. Taken together, these results suggest the therapeutic potential of EV-RNAs to induce the rescue of beta cell function.

Finally, miRNAs have been suggested as potential biomarkers for both type 1 and type 2 diabetes [150]. Recently, Garcia-Contreras et al. [151] have shown that plasmaderived EVs express a distinct signature in long lasting diabetes. Several deregulated miRNAs have been shown to be involved in diabetes progression. Barutta et al. [152] studied urinary EVs in incipient diabetic nephropathy showing an enrichment of miR-130a and miR-145 and a reduction of miR-155 and miR-424 in patients with microalbuminuria. In an experimental model of diabetic nephropathy, a similar upregulation of miR-145 in urinary EVs as well as in glomeruli was observed [152]. In vitro experiments showed that high glucose exposure of mesangial cells upregulated miR-145 with consequent increased expression of this miRNA in secreted EVs [152]. Since tissue-specific EVs may allow monitoring of transplanted tissue rejection, EVs could be also used as biomarkers to monitor the outcome of islet transplantation [153]. Moreover, it has been recently suggested that EVs carrying small RNAs released from MSCs may act as immune modulators to improve islet transplantation [154]. In fact, MSC-derived EVs have been already demonstrated to modulate immunity in type 1 diabetes inducing the formation of regulatory dendritic cells $[155,156]$.

5.3. Atherosclerosis. Dysfunctional adipose tissue and proinflammatory signals of metabolic syndrome are associated to the development of atherosclerosis, a condition characterized by a low-grade chronic inflammation of arterial wall $[157,158]$. The process is initiated by endothelial damage and followed by deposition of lipoproteins in the subendothelial place. Beside signaling and molecular regulatory pathways critical for the formation and evolution of the atherosclerotic plaques, miRNAs are considered crucial modulators at a fine tune level of the different players implicated in the pathophysiological processes of atherosclerosis. In response to different stimuli, miRNAs such as the miR181 family are suggested to be capable of modifying the balance of pro- and anti-inflammatory molecules implicated in the pathogenesis of atherosclerosis. The miR-181 family has a crucial role in vascular inflammation by regulation of signaling pathways and targets known to be critical for endothelium activation and immunity, thus contributing to the onset and development of vascular inflammatory diseases [159]. Several miRNAs involved in lipid metabolism have emerged as contributors of the pathogenic process of atherosclerosis such as miR-33 [160, 161], miR-27a/b [162, 163], and miR-122 [164]. miRNAs mediating the endothelial damage induced by disturbed flow have been identified and extensively studied (see [165] for review). In situations of shear stress, it has been shown that the increasing of the Kruppellike factor (KLF2) transcription factor induced the expression of functional miR-143/miR-145 cluster which was loaded in endothelial cell EVs and taken up by vascular smooth muscle cells in coculture [166], with acquisition of a contractile phenotype and stabilization of endothelium. Noteworthy, EVs from endothelial cells were able to decrease 
atherosclerotic lesion formation in vivo in the aorta of $\mathrm{ApoE}^{-1-}$ mice in a miR-143/miR-145-dependent manner exerting an atheroprotective effect [166]. In another study, the exchange of miR-143/miR-145 through intercellular tunneling nanotubes has been shown to occur between vascular smooth muscle cells and endothelial cells resulting also in this case in vessel stabilization [167]. EVs derived from vascular smooth muscle cells overexpressing Kruppellike factor 5 (KLF5) contained miR-155 and were able to promote atherosclerotic progression in vitro and in vivo. Thus, EVs could either promote or prevent atherosclerosis based on their RNA content [168]. In a recent study, de Gonzalo-Calvo et al. [169] investigated the miRNA content in EVs released from human coronary artery smooth muscle cells (CASMC) and its modification after exposure to atherogenic lipoproteins. Interestingly, these miRNA modifications were reproduced in the plasma of patients with familial hypercholesterolemia (FH). Among miRNAs deregulated by atherogenic lipoproteins, plasma miR-130a was suggested as potential biomarker of significant coronary atherosclerosis, and miR-24-3p and miR-130a present in circulating EVs as potential biomarkers for FH [169].

\section{Thyroid Disorders}

The thyroid gland is one of the largest endocrine glands in the body [170], and EVs containing undegraded thyroglobulin ( $\mathrm{Tg}$ ) have been suggested as an alternative way to conventional exocytosis of $\mathrm{Tg}[170,171]$. The presence of Tg-containing EVs in bovine serum [172] suggests the physiological involvement of this mechanism in the hormone release into circulation. In pathophysiological conditions, such as subclinical hypothyroidism, an increased number of preapoptotic vesicles might promote endothelial dysfunction and cardiovascular risk [173]. Although the precise mechanisms of autoimmunity are still under investigation [174], it is well known that EVs can modulate immune response [175]. Recent studies highlight the importance of an equilibrium between $\mathrm{T}$ effector and $\mathrm{T}$ regulatory cells to preserve the immune tolerance in thyroid, and of its alterations in the development of the autoimmune thyroid disease (AITD) [176]. Increasing evidence suggests a role of EVs also in thyroid autoimmune disorders. Graves' disease (GD) patients have higher levels of EVs in blood that are significantly reduced after antithyroid therapy with thiamazole [177]. The increase of circulating EVs most likely reflects the activation of immune and inflammatory processes and the resulting cell apoptosis. In addition, patients with GD have higher number of both E-selectin and VE-cadherin-positive EVs, suggesting endothelial dysfunction. The increase in monocyte-EVs indicates an activation and an increased turnover of monocytes. Based on these findings, EVs have been candidate biomarkers for diagnosis and prognosis of GD [177]. In human AITD, EVs seem to have a relevant role in the modulation of the inflammatory response since circulating EVs regulate Tregs and Th17 differentiation [178]. In particular, an increase in platelet-derived EVs and a decrease in leukocyte and endothelial cell-derived EVs have been detected in AITD patients compared to healthy controls. Of note, patient-derived EVs inhibited the in vitro differentiation of T regulatory cells and induced the differentiation of proinflammatory Th17 cells. RNA dysregulation, including both miRNAs and lncRNAs, has been associated to the pathogenesis of AITD [176, 179-181]. EVs derived from AITD patients showed a higher expression of miR146a and miR-155, involved in the differentiation and function of innate and adaptive immunity [178]. Both of these miRNAs are instrumental for function and development of Treg cells. miR-155 also favors the development of inflammatory T cells including Th17 cells. miR-146a and miR-155 can induce immune cell unbalance characteristic of AITD patients by targeting the SMAD family member 4 (SMAD4) [178]. Circulating EVs may mediate the crosstalk between immune cells, leading to the promotion of cytokine expression in peripheral blood mononuclear cells (PBMCs) and contributing to GD pathogenesis [182]. In particular, four miRNAs (miR-92a-3p, miR-23b-5p, miR-339-5p, and let7g$3 p)$ have been detected in EVs [183], suggesting their role in the upregulated cytokine production in intractable GD. The coincubation of EVs isolated from GD patients' sera can stimulate the mRNA expression of IL- $1 \beta$ and TNF- $\alpha$ in PBMCs, compared with EVs from GD patients in remission or from healthy controls [182]. GD patients in remission show an increase in circulating miR-23b-5p and miR-92a$3 p$ and a decrease of let-7g-3p and miR-339-5p compared to intractable GD patients [182]. The higher expression of these two miRNAs suggests their role as regulators of immune suppression in proinflammatory mechanisms of autoimmune disorders and their association to disease's remission. In addition, miR-339-5p is decreased in GD patients in remission versus intractable GD patients and regulates the expression of sodium-iodine symporter. This protein is involved in the response to radioactive iodine (RAI) therapy [184], a treatment for hyperactive thyroid states including thyroid cancer and Graves' disease [185]. Together, these studies candidate EVs as accessible biomarkers for monitoring or predicting disease activity as well as therapy outcomes in thyroid diseases.

\section{The Role of EVs in Preeclampsia}

EVs and their RNA cargo have been intensively studied for their role in physiology and pathophysiology in the context of reproduction such as sperm maturation, ovarian follicle and oocyte maturation, as well as fertilization, and pregnancy (as previously reviewed $[186,187]$ ). During pregnancy, placental EVs physiologically increase their concentration into circulation and mediate several biological processes, including endometrium remodeling and immunological communication between the mother and the fetus [188-192]. For instance, hypoxia during early pregnancy induces the release from cytotrophoblast cells and placental MSCs of a higher number of EVs with different contents and activities $[193,194]$. EVs have been reported to contribute to spiral artery remodeling essential to provide a satisfactory nutrient exchange at the maternal-fetal interface [195]. One example of EV immunological properties is represented by their capacity to confer viral resistance. In fact, both 
placenta and trophoblast-derived EVs are able to induce resistance of recipient cells against viral infections [196, 197]. Delorme-Axford et al. [196] demonstrated that this mechanism is mediated by the transfer of specific placental miRNAs. Here, we focus on preeclampsia (PE) and the purported role of EVs. Preeclampsia is a multisystem pregnancy disorder that is associated with major maternal and neonatal morbidities [198, 199]. The cellular mechanisms triggering the development and the progression of $\mathrm{PE}$ are still not completely elucidated [200]. PE is characterized by hypertension and a decreased utero-placental blood flow linked with impaired trophoblast invasion. Moreover, hypoxia of the placenta promotes the release of harmful substances into the maternal and feto-placental circulation leading to endothelial dysfunction [201]. Increasing evidence suggests that EVs contribute to the initiation and progression of PE by mediating the complex interactions at the maternalfetal interface [192, 200-202]. In normal pregnancy, EVs released from the syncytiotrophoblast (STB) (STB-EVs) contribute to communication between the maternal endometrium and the embryo [203]. In PE, STB-EVs are released in significantly increased number and show proinflammatory, procoagulant, and antiangiogenic activities, implicating them in the maternal systemic inflammation and endothelial dysfunction [204, 205]. EVs promote vasculogenesis and angiogenesis possibly by transferring miRNAs [201]. Placental EVs contain placental-specific molecules, including proteins (e.g., placental alkaline phosphatase (PLAP)) and miRNAs (e.g., chromosome 19 miRNA cluster) [206, 207]. EVs can also transfer placental-specific miRNA (miR-571a$3 p$ ) as it has been shown into human Treg cells and Jurkat leukemic T-cell line, inducing the repression of a gene target (PRKG1) [208]. Increasing studies have highlighted the potential use of EVs and placenta-derived miRNAs as PE diagnostic tools $[192,205,209,210]$. In fact, EVs are increased in PE maternal blood [191] and early onset PE [211]. Oxygen tension and hypoxia can modulate the release and the content of EVs from placental and trophoblast cells [193, 194, 212-214]. Using an in vitro model of PE, it has been demonstrated an alteration of miRNA cargo in a specific subpopulation of STB-EVs, with a downregulation of miR-517a, miR-517b, and miR-141 [215]. In a recent study, Salomon et al. [216] demonstrated an increase of total and placenta-EVs in plasma of $\mathrm{PE}$ pregnancies compared with healthy subjects. Importantly, EVs in $\mathrm{PE}$ patients showed a different content of miRNAs, mainly related to biological processes dysregulated in PE such as migration, placenta development, and angiogenesis. Among miRNAs, the authors identified the upregulation of miR-486-1-5p and miR-486-2-5p as candidate biomarkers to distinguish $\mathrm{PE}$ and normal pregnancies for the early detection of women at risk [216]. Therefore, it is plausible that EVs and their miRNA cargo could be useful as early biomarkers of $\mathrm{PE}$ thus improving pregnancy outcomes through the prevention and the reduction of PE severity. In the future, more information about the role of EVs and their associated RNAs will provide a better understanding as to their capacity to modulate gene targets, endothelial dysfunction, and angiogenesis.

\section{Conclusion}

In conclusion, this review summarizes the current knowledge on the role of noncoding RNAs shuttled by EVs in endocrine diseases. EVs may act locally as paracrine mediators and/or at distant sites being released in biological fluids. RNAs contained in EVs are described to be essential mediators of cell communication in endocrine physiopathology. These molecules carried by EVs can modulate the gene expression and the biological function of target cells. The majority of studies have focused on the role of miRNAs carried by EVs since small RNAs are the RNA species more abundant in EVs [205]. Although investigation on EV-lncRNAs and other noncoding RNAs is relatively at the beginning, the evidence suggests their key role in association to miRNAs in regulation of the endocrine system.

EVs and their associated noncoding RNAs are involved in the physiological cellular communication in endocrine organs. In the pancreas, EVs mediate the exchange of information between beta cells with endothelial cells and adjacent beta cells $[129,130]$. Through their RNA cargo, EVs regulate beta cell function, insulin secretion, and angiogenesis [131]. In the liver, they can control the metabolic homeostasis and modulate glucose and lipid metabolism [119, 120]. EVs are also essential mediators of normal communication in endocrine glands, such as thyroid, and in the immune system $[171,172,175,217]$. EV modulation of immune response and angiogenesis suggests also their involvement in reproductive processes. In particular, during pregnancy, EVs and their cargo mediate the immunological interaction at the maternal-fetus interface and control endothelial remodeling [188-192, 195]. Moreover, RNAs carried by EVs have been involved also in the establishment and progression of several endocrine diseases, such as thyroid autoimmunity disorders, complicated pregnancy, and in metabolic dysfunctions, including obesity and diabetes, and their related manifestations. In metabolic syndrome, EV-associated noncoding RNAs can modulate biological processes (oxidative stress, inflammation, insulin signaling, adipogenesis, and angiogenesis) which can promote disease progression. EVs released by macrophages of adipose tissue can modulate liver and muscle glucose and insulin metabolism, favoring diabetes [103]. Skeletal muscle can also modulate the fate of pancreatic beta cells through EV-RNAs leading to insulin resistance [143]. In addition, adipocytes can release EVs that can activate macrophages and lead to inflammation and insulin resistance in obese subjects [105]. EVs from adipose tissue can mediate liver insults and promote chronic inflammation [109, 127] and thus favor the atherosclerosis progression [157, 158]. The modulatory role of EVs in immune response and inflammation has been reported in autoimmune endocrine disorders [182] and in preeclampsia [204, 205]. A better understanding of the role of EVs and their molecular content in pathological and physiological conditions may provide insight for new therapeutic strategies. EVs and their associated noncoding RNAs could be targeted as therapeutic approach. When EV-associated RNAs positively correlate with the progression of endocrine diseases, interventions aimed to reduce their release or their bioactive cargo could 
TABLE 2: Most relevant EV-miRNAs for biomarker application in endocrine diseases.

\begin{tabular}{|c|c|c|c|c|c|}
\hline miRNA & Change & Source & \multicolumn{2}{|c|}{ Disease } & Reference \\
\hline$m i R-23 b$ & $\uparrow$ & Adipocyte-derived EVs & Obesity & Metabolic syndrome & {$[107]$} \\
\hline$m i R-122$ & $\uparrow$ & Circulating EVs & NAFLD & Metabolic syndrome & {$[125]$} \\
\hline \multirow{2}{*}{$\operatorname{miR}-130 a$} & $\uparrow$ & Urinary EVs & Diabetic nephropathy & Metabolic syndrome & {$[152]$} \\
\hline & $\downarrow$ & Circulating EVs & Coronary atherosclerosis & Metabolic syndrome & {$[169]$} \\
\hline$m i R-141$ & $\downarrow$ & STB-derived EVs & \multicolumn{2}{|c|}{ Preeclampsia } & {$[215]$} \\
\hline$m i R-145$ & $\uparrow$ & Urinary EVs & Diabetic nephropathy & Metabolic syndrome & {$[152]$} \\
\hline$m i R-146 a$ & $\uparrow$ & Circulating EVs & AITD & Thyroid disorders & {$[178]$} \\
\hline$m i R-148 b$ & $\downarrow$ & Adipocyte-derived EVs & Obesity & Metabolic syndrome & [107] \\
\hline \multirow{2}{*}{$m i R-155$} & $\downarrow$ & Urinary EVs & Diabetic nephropathy & Metabolic syndrome & {$[152]$} \\
\hline & $\uparrow$ & Circulating EVs & AITD & Thyroid disorders & {$[178]$} \\
\hline$m i R-192$ & $\uparrow$ & Circulating EVs & NAFLD & Metabolic syndrome & {$[125]$} \\
\hline$m i R-424$ & $\downarrow$ & Urinary EVs & Diabetic nephropathy & Metabolic syndrome & {$[152]$} \\
\hline$m i R-486-1-5 p$ & $\uparrow$ & Circulating EVs & \multicolumn{2}{|c|}{ Preeclampsia } & {$[216]$} \\
\hline$m i R-486-2-5 p$ & $\uparrow$ & Circulating EVs & \multicolumn{2}{|c|}{ Preeclampsia } & {$[216]$} \\
\hline$m i R-517 a$ & $\downarrow$ & STB-derived EVs & \multicolumn{2}{|c|}{ Preeclampsia } & [215] \\
\hline$m i R-517 b$ & $\downarrow$ & STB-derived EVs & \multicolumn{2}{|c|}{ Preeclampsia } & [215] \\
\hline$m i R-4269$ & $\downarrow$ & Adipocyte-derived EVs & Obesity & Metabolic syndrome & {$[107]$} \\
\hline$m i R-4429$ & $\uparrow$ & Adipocyte-derived EVs & Obesity & Metabolic syndrome & {$[107]$} \\
\hline
\end{tabular}

EV: extracellular vesicle; NAFLD: nonalcoholic fatty liver disease; STB: syncytiotrophoblast; AITD: autoimmune thyroid disease. miRNA expression change: $\uparrow$ : increased expression; $\downarrow$ : reduced expression.

inhibit disease. For instance, miR-320 contained in EVs from diabetic rat can inhibit angiogenesis, but a decreased miR-320 content in EVs can restore and have a therapeutic impact [218]. Otherwise, the loading of EVs with therapeutic RNAs can have a beneficial relevance and the enrichment of endothelial cell-derived EVs with miR-146a demonstrated to attenuate dementia-like pathology following administration in diabetic $\mathrm{db} / \mathrm{db}$ mice [219].

On the other hand, since EVs carry the molecular signature of the cell of origin, they can be exploited as diagnostic tools. In fact, EVs present in the biological fluids vary in number and molecular content depending on the physiological or pathological conditions. In particular, noncoding RNAs present in EVs may provide a picture of ongoing biological processes in the organism. In fact, vesicleincluded RNA species are protected from enzyme degradation and are an accessible source of RNAs released in the biological fluid by different cell types and organs. To date, EVs represent a potential diagnostic instrument and increasing studies are highlighting their utility to identify endocrine diseases. In fact, a recent clinical trial has begun to investigate EVs released by beta cells isolated from plasma of diabetes mellitus patients to identify islet-specific antigens (ClinicalTrials.gov identifier: NCT03106246). Likewise, EVassociated noncoding RNAs are arising interest as disease's biomarkers and they are currently investigated in a clinical trial focused on cholangiocarcinoma (ClinicalTrials.gov identifier: NCT03102268). In endocrine diseases, current results on EV-associated noncoding RNAs here presented and summarized in Table 2 give hope to exploit them as an easy and noninvasive diagnostic instrument. Moreover, RNA cargo of EVs could provide clinically useful information and be exploited to staging and in predicting response to therapy. In that context, the optimal definition of the EV isolation procedures is an essential challenge to improve the purity of starting material for downstream analysis. In particular, standardization of techniques will better define the presence of coisolated free circulating RNAs. These non-EVassociated molecules are connected to protein (e.g., Ago2) or lipoprotein complexes, and they can be coisolated with EVassociated RNAs during isolation procedures [55]. Different $\mathrm{EV}$ isolation techniques allow different grades of non-EV RNA contamination and can lead to discordant results in the literature. In future, the constant progress and consensus in technology platforms may solve the presence of discrepancies due to technical methodologies which still exist.

\section{Abbreviations}

AITD: $\quad$ Autoimmune thyroid disease

ALIX: $\quad$ ALG-2-interacting protein X or

programmed cell death 6 interacting protein

ALT: $\quad$ Alanine aminotransferase

ARF6: $\quad$ ADP-ribosylation factor 6

ARRDC1: Arrestin domain-containing protein-1

ASCs: $\quad$ Adipose mesenchymal stem cells

CASMC: $\quad$ Coronary artery smooth muscle cells

CDAA: Choline deficient L-amino acid

ceRNAs: Competing endogenous RNAs

cRNAs: Circular RNAs

DM: Diabetes mellitus

EPCs: $\quad$ Endothelial progenitor cells

Erk1/2 MAPK: Extracellular signal-regulated kinase 1/2 mitogen-activated protein kinase

ESCRT: $\quad$ Endosomal sorting complex required for transport 


\begin{tabular}{|c|c|}
\hline EVs: & Extracellular vesicles \\
\hline FGF21: & Fibroblast growth factor- 21 \\
\hline $\mathrm{FH}:$ & Familial hypercholesterolemia \\
\hline$g:$ & Centrifugal forces \\
\hline GD: & Graves' disease \\
\hline hnRNPA2B1: & $\begin{array}{l}\text { Heterogeneous nuclear ribonucleoprotein } \\
\text { A2B1 }\end{array}$ \\
\hline Ins1: & Insulin gene 1 \\
\hline Ins2: & Insulin gene 2 \\
\hline IR: & Insulin resistance \\
\hline KLF2: & Kruppel-like factor \\
\hline KLF5: & Kruppel-like factor 5 \\
\hline lncRNAs: & Long noncoding RNAs \\
\hline miRNAs: & MicroRNAs \\
\hline Myrip: & Myosin VIIA and Rab-interacting protein \\
\hline MSCs: & Mesenchymal stromal cells \\
\hline MVB: & Multivesicular bodies \\
\hline NAFLD: & Nonalcoholic fatty liver disease \\
\hline NASH: & Nonalcoholic steatohepatitis \\
\hline Pax-6: & Paired box protein Pax-6 \\
\hline PBMCs: & Peripheral blood mononuclear cells \\
\hline PE: & Preeclampsia \\
\hline PEG: & Polyethylene glycol \\
\hline PGCI $\alpha$ : & $\begin{array}{l}\text { Peroxisome proliferator-activated receptor } \\
\text { gamma coactivator } 1 \text {-alpha }\end{array}$ \\
\hline PM: & Plasma membrane \\
\hline PPAR $\gamma:$ & $\begin{array}{l}\text { Peroxisome proliferator-activated receptor } \\
\text { gamma }\end{array}$ \\
\hline RAI: & Radioactive iodine \\
\hline RISC: & RNA-induced silencing complex \\
\hline ROCK1: & $\begin{array}{l}\text { Rho-associated coiled-coil containing } \\
\text { protein kinase } 1\end{array}$ \\
\hline rRNAs: & Ribosomal RNAs \\
\hline SEC: & Size-exclusion chromatography \\
\hline siRNAs: & Small interference RNAs \\
\hline SMAD4: & SMAD family member 4 \\
\hline snoRNAs: & Small nucleolar RNAs \\
\hline snRNAs: & Small nuclear RNAs \\
\hline STB: & Syncytiotrophoblast \\
\hline T1D: & Type 1 diabetes \\
\hline T2D: & Type 2, non-insulin-dependent diabetes \\
\hline Tg: & Thyroglobulin \\
\hline TGF $\beta$ : & Transforming growth factor $\beta$ \\
\hline TRAIL: & $\begin{array}{l}\text { Tumor necrosis factor-related apoptosis- } \\
\text { inducing ligand }\end{array}$ \\
\hline tRNAs: & Transfer RNAs \\
\hline TSG101: & Tumour susceptibility gene 101 protein \\
\hline UCP-1: & Uncoupling protein 1 \\
\hline vtRNAs: & Vault RNAs \\
\hline YBX1: & RNA-binding protein Y-box protein I \\
\hline yRNAs: & Cytoplasmic Y RNAs. \\
\hline
\end{tabular}

\section{Conflicts of Interest}

The authors declare that there is no conflict of interest regarding the publication of this article. The affiliation of Ciro Tetta to Unicyte AG does not lead to any conflict of interest on the present review article.

\section{Acknowledgments}

This study was supported by Unicyte AG Grant "nano EVs" to $2 \mathrm{i} 3 \mathrm{~T}$ Scarl.

\section{References}

[1] J. S. Mattick and I. V. Makunin, "Non-coding RNA," Human Molecular Genetics, vol. 15, Supplement 1, pp. R17-R29, 2006.

[2] M. P. Kowalski and T. Krude, "Functional roles of noncoding Y RNAs," The International Journal of Biochemistry \& Cell Biology, vol. 66, pp. 20-29, 2015.

[3] L. Wang, D. C. Samuels, S. Zhao, Y. Xiang, Y. Y. Zhao, and Y. Guo, "Current research on non-coding ribonucleic acid (RNA)," Genes, vol. 8, no. 12, 2017.

[4] M. Amort, B. Nachbauer, S. Tuzlak et al., "Expression of the vault RNA protects cells from undergoing apoptosis," Nature Communications, vol. 6, no. 1, p. 7030, 2015.

[5] P. F. Stadler, J. J. Chen, J. Hackermüller et al., "Evolution of vault RNAs," Molecular Biology and Evolution, vol. 26, no. 9, pp. 1975-1991, 2009.

[6] M. Jinek and J. A. Doudna, "A three-dimensional view of the molecular machinery of RNA interference," Nature, vol. 457, no. 7228, pp. 405-412, 2009.

[7] M. Esteller, "Non-coding RNAs in human disease," Nature Reviews Genetics, vol. 12, no. 12, pp. 861-874, 2011.

[8] X. Shi, M. Sun, H. Liu, Y. Yao, and Y. Song, "Long noncoding RNAs: a new frontier in the study of human diseases," Cancer Letters, vol. 339, no. 2, pp. 159-166, 2013.

[9] S. Hombach and M. Kretz, "Non-coding RNAs: classification, biology and functioning," in Advances in Experimental Medicine and Biology, O. Slaby and G. Calin, Eds., vol. 937 of Adv Exp Med Biol, pp. 3-17, Springer, Cham, 2016.

[10] Q. Gong and G. Su, "Roles of miRNAs and long noncoding RNAs in the progression of diabetic retinopathy," Bioscience Reports, vol. 37, no. 6, article BSR20171157, 2017.

[11] N. Cheng and Y. Guo, "Long noncoding RNA NEAT1 promotes nasopharyngeal carcinoma progression through regulation of miR-124/NF- $\kappa \mathrm{B}$ pathway," Onco Targets and Therapy, vol. 10, pp. 5843-5853, 2017.

[12] W. Ding, J. Ren, H. Ren, and D. Wang, "Long noncoding RNA HOTAIR modulates MiR-206-mediated Bcl-w signaling to facilitate cell proliferation in breast cancer," Scientific Reports, vol. 7, no. 1, article 17261, 2017.

[13] Z. Q. Gao, J. Wang, D.-H. Chen et al., "Long non-coding RNA GAS5 suppresses pancreatic cancer metastasis through modulating miR-32-5p/PTEN axis," Cell \& Bioscience, vol. 7, no. 1, p. $66,2017$.

[14] W. Liu, C. Ma, B. Yang, C. Yin, B. Zhang, and Y. Xiao, "LncRNA Gm15290 sponges miR-27b to promote PPAR $\gamma$ induced fat deposition and contribute to body weight gain in mice," Biochemical and Biophysical Research Communications, vol. 493, no. 3, pp. 1168-1175, 2017.

[15] J. $\mathrm{Xu}$ and $\mathrm{Y} . \mathrm{Xu}$, "The lncRNA MEG3 downregulation leads to osteoarthritis progression via miR-16/SMAD7 axis," Cell \& Bioscience, vol. 7, no. 1, p. 69, 2017.

[16] B. Long, N. Li, X. X. Xu et al., "Long noncoding RNA FTX regulates cardiomyocyte apoptosis by targeting miR-29b1-5p and Bcl212," Biochemical and Biophysical Research Communications, vol. 495, no. 1, pp. 312-318, 2018. 
[17] B. Y. Zhang, Z. Jin, and Z. Zhao, "Long intergenic noncoding RNA 00305 sponges miR-136 to regulate the hypoxia induced apoptosis of vascular endothelial cells," Biomedicine \& Pharmacotherapy, vol. 94, pp. 238-243, 2017.

[18] D. Zhang, H. Lee, J. A. Haspel, and Y. Jin, "Long noncoding RNA FOXD3-AS1 regulates oxidative stress-induced apoptosis via sponging microRNA-150," The FASEB Journal, vol. 31, no. 10, pp. 4472-4481, 2017.

[19] L. Zhang, X. Sun, S. Chen et al., "Long noncoding RNA DANCR regulates $m i R-1305-S m a d ~ 4$ axis to promote chondrogenic differentiation of human synovium-derived mesenchymal stem cells," Bioscience Reports, vol. 37, no. 4, article BSR20170347, 2017.

[20] C. Théry, M. Ostrowski, and E. Segura, "Membrane vesicles as conveyors of immune responses," Nature Reviews Immunology, vol. 9, no. 8, pp. 581-593, 2009.

[21] J. Lötvall, A. F. Hill, F. Hochberg et al., "Minimal experimental requirements for definition of extracellular vesicles and their functions: a position statement from the International Society for Extracellular Vesicles," Journal of Extracellular Vesicles, vol. 3, no. 1, article 26913, 2014.

[22] N. Iraci, T. Leonardi, F. Gessler, B. Vega, and S. Pluchino, "Focus on extracellular vesicles: physiological role and signalling properties of extracellular membrane vesicles," International Journal of Molecular Sciences, vol. 17, no. 2, p. 171, 2016.

[23] M. Colombo, G. Raposo, and C. Théry, "Biogenesis, secretion, and intercellular interactions of exosomes and other extracellular vesicles," Annual Review of Cell and Developmental Biology, vol. 30, no. 1, pp. 255-289, 2014.

[24] J. Ratajczak, K. Miekus, M. Kucia et al., "Embryonic stem cellderived microvesicles reprogram hematopoietic progenitors: evidence for horizontal transfer of mRNA and protein delivery," Leukemia, vol. 20, no. 5, pp. 847-856, 2006.

[25] K. Ridder, S. Keller, M. Dams et al., "Extracellular vesiclemediated transfer of genetic information between the hematopoietic system and the brain in response to inflammation," PLoS Biology, vol. 12, no. 6, article e1001874, 2014.

[26] K. Ridder, A. Sevko, J. Heide et al., "Extracellular vesicle-mediated transfer of functional RNA in the tumor microenvironment," Oncoimmunology, vol. 4, no. 6, article e1008371, 2015.

[27] A. Zomer, C. Maynard, F. J. Verweij et al., "In vivo imaging reveals extracellular vesicle-mediated phenocopying of metastatic behavior," Cell, vol. 161, no. 5, pp. 1046-1057, 2015.

[28] C. P. Lai, E. Y. Kim, C. E. Badr et al., "Visualization and tracking of tumour extracellular vesicle delivery and RNA translation using multiplexed reporters," Nature Communications, vol. 6, no. 1, article 7029, 2015.

[29] B. Zhang, R. W. Yeo, K. H. Tan, and S. K. Lim, "Focus on extracellular vesicles: therapeutic potential of stem cell-derived extracellular vesicles," International Journal of Molecular Sciences, vol. 17, no. 2, p. 174, 2016.

[30] S. Bruno, F. Collino, A. Iavello, and G. Camussi, "Effects of mesenchymal stromal cell-derived extracellular vesicles on tumor growth," Frontiers in Immunology, vol. 5, p. 382, 2014.

[31] C. Grange, M. Tapparo, F. Collino et al., "Microvesicles released from human renal cancer stem cells stimulate angiogenesis and formation of lung premetastatic niche," Cancer Research, vol. 71, no. 15, pp. 5346-5356, 2011.
[32] C. A. Sánchez, E. I. Andahur, R. Valenzuela et al., "Exosomes from bulk and stem cells from human prostate cancer have a differential microRNA content that contributes cooperatively over local and pre-metastatic niche," Oncotarget, vol. 7, no. 4, pp. 3993-4008, 2016.

[33] M. Tkach and C. Théry, "Communication by extracellular vesicles: where we are and where we need to go," Cell, vol. 164, no. 6, pp. 1226-1232, 2016.

[34] S. Kholia, A. Ranghino, P. Garnieri et al., "Extracellular vesicles as new players in angiogenesis," Vascular Pharmacology, vol. 86, pp. 64-70, 2016.

[35] C. Tricarico, J. Clancy, and C. D'Souza-Schorey, "Biology and biogenesis of shed microvesicles," Small GTPases, vol. 8, no. 4, pp. 220-232, 2016.

[36] J. C. Akers, D. Gonda, R. Kim, B. S. Carter, and C. C. Chen, "Biogenesis of extracellular vesicles (EV): exosomes, microvesicles, retrovirus-like vesicles, and apoptotic bodies," Journal of Neuro-Oncology, vol. 113, no. 1, pp. 1-11, 2013.

[37] J. Kowal, M. Tkach, and C. Théry, "Biogenesis and secretion of exosomes," Current Opinion in Cell Biology, vol. 29, pp. 116-125, 2014.

[38] V. Hyenne, A. Apaydin, D. Rodriguez et al., "RAL-1 controls multivesicular body biogenesis and exosome secretion," The Journal of Cell Biology, vol. 211, no. 1, pp. 27-37, 2015.

[39] E. R. Abels and X. O. Breakefield, "Introduction to extracellular vesicles: biogenesis, RNA cargo selection, content, release, and uptake," Cellular and Molecular Neurobiology, vol. 36, no. 3, pp. 301-312, 2016.

[40] Y. Zhang, D. Liu, X. Chen et al., "Secreted monocytic miR150 enhances targeted endothelial cell migration," Molecular Cell, vol. 39, no. 1, pp. 133-144, 2010.

[41] F. Collino, M. C. Deregibus, S. Bruno et al., "Microvesicles derived from adult human bone marrow and tissue specific mesenchymal stem cells shuttle selected pattern of miRNAs," PLoS One, vol. 5, no. 7, article e11803, 2010.

[42] B. J. Goldie, M. D. Dun, M. Lin et al., "Activity-associated miRNA are packaged in Map1b-enriched exosomes released from depolarized neurons," Nucleic Acids Research, vol. 42, no. 14, pp. 9195-9208, 2014.

[43] C. C. Li, S. A. Eaton, P. E. Young et al., "Glioma microvesicles carry selectively packaged coding and non-coding RNAs which alter gene expression in recipient cells," RNA Biology, vol. 10, no. 8, pp. 1333-1344, 2013.

[44] C. Villarroya-Beltri, F. Baixauli, C. Gutiérrez-Vázquez, F. Sánchez-Madrid, and M. Mittelbrunn, "Sorting it out: regulation of exosome loading," Seminars in Cancer Biology, vol. 28, no. 3, p. 13, 2014.

[45] A. Iavello, V. S. Frech, C. Gai, M. C. Deregibus, P. J. Quesenberry, and G. Camussi, "Role of Alix in miRNA packaging during extracellular vesicle biogenesis," International Journal of Molecular Medicine, vol. 37, no. 4, pp. 958-966, 2016.

[46] S. A. Melo, H. Sugimoto, J. T. O'Connell et al., "Cancer exosomes perform cell-independent microRNA biogenesis and promote tumorigenesis," Cancer Cell, vol. 26, no. 5, pp. 707-721, 2014.

[47] C. Villarroya-Beltri, C. Gutiérrez-Vázquez, F. Sánchez-Cabo et al., "Sumoylated hnRNPA2B1 controls the sorting of miRNAs into exosomes through binding to specific motifs," Nature Communications, vol. 4, article 2980, 2013. 
[48] M. J. Shurtleff, M. M. Temoche-Diaz, K. V. Karfilis, S. Ri, and R. Schekman, "Y-box protein 1 is required to sort microRNAs into exosomes in cells and in a cell-free reaction," eLife, vol. 5, 2016.

[49] D. J. Cha, J. L. Franklin, Y. Dou et al., "KRAS-dependent sorting of miRNA to exosomes," eLife, vol. 4, article e07197, 2015.

[50] A. J. McKenzie, D. Hoshino, N. H. Hong et al., "KRAS-MEK signaling controls Ago2 sorting into exosomes," Cell Reports, vol. 15, no. 5, pp. 978-987, 2016.

[51] J. P. Tosar, F. Gámbaro, J. Sanguinetti, B. Bonilla, K. W. Witwer, and A. Cayota, "Assessment of small RNA sorting into different extracellular fractions revealed by highthroughput sequencing of breast cell lines," Nucleic Acids Research, vol. 43, no. 11, pp. 5601-5616, 2015.

[52] B. W. van Balkom, A. S. Eisele, D. M. Pegtel, S. Bervoets, and M. C. Verhaar, "Quantitative and qualitative analysis of small RNAs in human endothelial cells and exosomes provides insights into localized RNA processing, degradation and sorting," Journal of Extracellular Vesicles, vol. 4, no. 1, article 26760, 2015.

[53] E. N. Nolte-'t Hoen, H. P. Buermans, M. Waasdorp, W. Stoorvogel, M. H. Wauben, and P. A. 't Hoen, "Deep sequencing of RNA from immune cell-derived vesicles uncovers the selective incorporation of small non-coding RNA biotypes with potential regulatory functions," Nucleic Acids Research, vol. 40, no. 18, pp. 9272-9285, 2012.

[54] U. Lambertz, M. E. Oviedo Ovando, E. J. Vasconcelos, P. J. Unrau, P. J. Myler, and N. E. Reiner, "Small RNAs derived from tRNAs and rRNAs are highly enriched in exosomes from both old and new world Leishmania providing evidence for conserved exosomal RNA packaging," BMC Genomics, vol. 16, no. 1, p. 151, 2015.

[55] B. Mateescu, E. J. Kowal, B. W. van Balkom et al., "Obstacles and opportunities in the functional analysis of extracellular vesicle RNA - an ISEV position paper," Journal of Extracellular Vesicles, vol. 6, no. 1, article 1286095, 2017.

[56] J. Van Deun, P. Mestdagh, R. Sormunen et al., "The impact of disparate isolation methods for extracellular vesicles on downstream RNA profiling," Journal of Extracellular Vesicle, vol. 3, no. 1, 2014.

[57] D. D. Taylor and S. Shah, "Methods of isolating extracellular vesicles impact down-stream analyses of their cargoes," Methods, vol. 87, pp. 3-10, 2015.

[58] G. Raposo, H. W. Nijman, W. Stoorvogel et al., "B lymphocytes secrete antigen-presenting vesicles," The Journal of Experimental Medicine, vol. 183, no. 3, pp. 1161-1172, 1996.

[59] C. Théry, S. Amigorena, G. Raposo, and A. Clayton, "Isolation and characterization of exosomes from cell culture supernatants and biological fluids," Current Protocols in Cell Biology, vol. 30, 2006, Chapter 3: Unit 3.22.

[60] K. W. Witwer, E. I. Buzás, L. T. Bemis et al., "Standardization of sample collection, isolation and analysis methods in extracellular vesicle research," Journal of Extracellular Vesicles, vol. 2, article 20360, 2013.

[61] M. P. Bard, J. P. Hegmans, A. Hemmes et al., "Proteomic analysis of exosomes isolated from human malignant pleural effusions," American Journal of Respiratory Cell and Molecular Biology, vol. 31, no. 1, pp. 114-121, 2004.

[62] S. Keller, J. Ridinger, A. K. Rupp, J. W. Janssen, and P. Altevogt, "Body fluid derived exosomes as a novel template for clinical diagnostics," Journal of Translational Medicine, vol. 9, no. 1, p. 86, 2011.

[63] A. Poliakov, M. Spilman, T. Dokland, C. L. Amling, and J. A. Mobley, "Structural heterogeneity and protein composition of exosome-like vesicles (prostasomes) in human semen," The Prostate, vol. 69, no. 2, pp. 159-167, 2009.

[64] C. Gardiner, D. Di Vizio, S. Sahoo et al., "Techniques used for the isolation and characterization of extracellular vesicles: results of a worldwide survey," Journal of Extracellular Vesicles, vol. 5, no. 1, article 32945, 2016.

[65] Y. Yuana, J. Levels, A. Grootemaat, A. Sturk, and R. Nieuwland, "Co-isolation of extracellular vesicles and high-density lipoproteins using density gradient ultracentrifugation," Journal of Extracellular Vesicles, vol. 3, no. 1, 2014.

[66] M. B. Herrera Sanchez, S. Previdi, S. Bruno et al., "Extracellular vesicles from human liver stem cells restore argininosuccinate synthase deficiency," Stem Cell Research \& Therapy, vol. 8, no. 1, p. 176, 2017.

[67] R. Cantin, J. Diou, D. Bélanger, A. M. Tremblay, and C. Gilbert, "Discrimination between exosomes and HIV-1: purification of both vesicles from cell-free supernatants," Journal of Immunological Methods, vol. 338, no. 1-2, pp. 21-30, 2008.

[68] J. Kowal, G. Arras, M. Colombo et al., "Proteomic comparison defines novel markers to characterize heterogeneous populations of extracellular vesicle subtypes," Proceedings of the National Academy of Sciences of the United States of America, vol. 113, no. 8, pp. E968-E977, 2016.

[69] R. Linares, S. Tan, C. Gounou, N. Arraud, and A. R. Brisson, "High-speed centrifugation induces aggregation of extracellular vesicles," Journal of Extracellular Vesicles, vol. 4, no. 1, article 29509, 2015.

[70] A. Cvjetkovic, J. Lötvall, and C. Lässer, "The influence of rotor type and centrifugation time on the yield and purity of extracellular vesicles," Journal of Extracellular Vesicles, vol. 3, no. 1, article 23111, 2014.

[71] R. Szatanek, J. Baran, M. Siedlar, and M. Baj-Krzyworzeka, "Isolation of extracellular vesicles: determining the correct approach (review)," International Journal of Molecular Medicine, vol. 36, no. 1, pp. 11-17, 2015.

[72] A. de Menezes-Neto, M. J. Sáez, I. Lozano-Ramos et al., "Sizeexclusion chromatography as a stand-alone methodology identifies novel markers in mass spectrometry analyses of plasma-derived vesicles from healthy individuals," Journal of Extracellular Vesicles, vol. 4, no. 1, article 27378, 2015.

[73] K. Blans, M. S. Hansen, L. V. Sørensen et al., "Pellet-free isolation of human and bovine milk extracellular vesicles by size-exclusion chromatography," Journal of Extracellular Vesicles, vol. 6, no. 1, article 1294340, 2017.

[74] J. L. Welton, J. P. Webber, L. A. Botos, M. Jones, and A. Clayton, "Ready-made chromatography columns for extracellular vesicle isolation from plasma," Journal of Extracellular Vesicles, vol. 4, no. 1, article 27269, 2015.

[75] L. Muller, C. S. Hong, D. B. Stolz, S. C. Watkins, and T. L. Whiteside, "Isolation of biologically-active exosomes from human plasma," Journal of Immunological Methods, vol. 411, pp. 55-65, 2014.

[76] I. Lozano-Ramos, I. Bancu, A. Oliveira-Tercero et al., "Sizeexclusion chromatography-based enrichment of extracellular vesicles from urine samples," Journal of Extracellular Vesicles, vol. 4, no. 1, article 27369, 2015. 
[77] J. Z. Nordin, Y. Lee, P. Vader et al., "Ultrafiltration with sizeexclusion liquid chromatography for high yield isolation of extracellular vesicles preserving intact biophysical and functional properties," Nanomedicine, vol. 11, no. 4, pp. 879-883, 2015.

[78] T. Baranyai, K. Herczeg, Z. Onódi et al., "Isolation of exosomes from blood plasma: qualitative and quantitative comparison of ultracentrifugation and size exclusion chromatography methods," PLoS One, vol. 10, no. 12, article e0145686, 2015.

[79] P. Li, M. Kaslan, S. H. Lee, J. Yao, and Z. Gao, "Progress in exosome isolation techniques," Theranostics, vol. 7, no. 3, pp. 789-804, 2017.

[80] L. G. Liang, M. Q. Kong, S. Zhou et al., "An integrated double-filtration microfluidic device for isolation, enrichment and quantification of urinary extracellular vesicles for detection of bladder cancer," Scientific Reports, vol. 7, article 46224, 2017.

[81] H. K. Woo, V. Sunkara, J. Park et al., "Exodisc for rapid, sizeselective, and efficient isolation and analysis of nanoscale extracellular vesicles from biological samples," ACS Nano, vol. 11, no. 2, pp. 1360-1370, 2017.

[82] N. Zarovni, A. Corrado, P. Guazzi et al., "Integrated isolation and quantitative analysis of exosome shuttled proteins and nucleic acids using immunocapture approaches," Methods, vol. 87, pp. 46-58, 2015.

[83] E. Zeringer, T. Barta, M. Li, and A. V. Vlassov, "Strategies for isolation of exosomes," Cold Spring Harbor Protocols, vol. 2015, no. 4, 2015.

[84] M. C. Deregibus, F. Figliolini, S. D'Antico et al., "Chargebased precipitation of extracellular vesicles," International Journal of Molecular Medicine, vol. 38, no. 5, pp. 13591366, 2016.

[85] M. L. Alvarez, M. Khosroheidari, R. R. Kanchi, and J. K. DiStefano, "Comparison of protein, microRNA, and mRNA yields using different methods of urinary exosome isolation for the discovery of kidney disease biomarkers," Kidney International, vol. 82, no. 9, pp. 1024-1032, 2012.

[86] D. D. Taylor, W. Zacharias, and C. Gercel-Taylor, "Exosome isolation for proteomic analyses and RNA profiling," Methods in Molecular Biology, vol. 728, pp. 235-246, 2011.

[87] S. Vienberg, J. Geiger, S. Madsen, and L. T. Dalgaard, "MicroRNAs in metabolism," Acta Physiologica, vol. 219, no. 2, pp. 346-361, 2017.

[88] W. Liu, H. Cao, C. Ye et al., "Hepatic miR-378 targets p110 $\alpha$ and controls glucose and lipid homeostasis by modulating hepatic insulin signalling," Nature Communications, vol. 5, p. 5684, 2014.

[89] V. Plaisance, G. Waeber, R. Regazzi, and A. Abderrahmani, "Role of microRNAs in islet beta-cell compensation and failure during diabetes," Journal of Diabetes Research, vol. 2014, Article ID 618652, 12 pages, 2014.

[90] A. Derghal, M. Djelloul, C. Airault et al., "Leptin is required for hypothalamic regulation of miRNAs targeting POMC 3'UTR," Frontiers in Cellular Neuroscience, vol. 9, no. 172, 2015.

[91] P. Arner and A. Kulyte, "MicroRNA regulatory networks in human adipose tissue and obesity," Nature Reviews Endocrinology, vol. 11, no. 5, pp. 276-288, 2015.

[92] M. A. Mori, T. Thomou, J. Boucher et al., "Altered miRNA processing disrupts brown/white adipocyte determination and associates with lipodystrophy," Journal of Clinical Investigation, vol. 124, no. 8, pp. 3339-3351, 2014.

[93] F. C. Reis, J. L. Branquinho, B. Brandão et al., "Fat-specific Dicer deficiency accelerates aging and mitigates several effects of dietary restriction in mice," Aging, vol. 8, no. 6, pp. 1201-1222, 2016.

[94] B. B. Brandão, B. A. Guerra, and M. A. Mori, "Shortcuts to a functional adipose tissue: the role of small non-coding RNAs," Redox Biology, vol. 12, pp. 82-102, 2017.

[95] R. C. Chang, W. Ying, F. W. Bazer, and B. Zhou, "MicroRNAs control macrophage formation and activation: the inflammatory link between obesity and cardiovascular diseases," Cell, vol. 3, no. 4, pp. 702-712, 2014.

[96] Y. Nakamachi, S. Kawano, M. Takenokuchi et al., "MicroRNA-124a is a key regulator of proliferation and monocyte chemoattractant protein 1 secretion in fibroblast-like synoviocytes from patients with rheumatoid arthritis," Arthritis and Rheumatism, vol. 60, no. 5, pp. 1294-1304, 2009.

[97] D. Zhu, C. Pan, L. Li et al., "MicroRNA-17/20a/106a modulate macrophage inflammatory responses through targeting signal-regulatory protein $\alpha$," The Journal of Allergy and Clinical Immunology, vol. 132, no. 2, pp. 426436.e8, 2013.

[98] C. N. Lumeng, J. B. DelProposto, D. J. Westcott, and A. R. Saltiel, "Phenotypic switching of adipose tissue macrophages with obesity is generated by spatiotemporal differences in macrophage subtypes," Diabetes, vol. 57, no. 12, pp. 32393246, 2008.

[99] I. D. Kilic, Y. Dodurga, B. Uludag et al., "microRNA -143 and -223 in obesity," Gene, vol. 560, no. 2, pp. 140-142, 2015.

[100] A. A. Chaudhuri, A. Y. So, N. Sinha et al., "MicroRNA-125b potentiates macrophage activation," The Journal of Immunology, vol. 187, no. 10, pp. 5062-5068, 2011.

[101] G. Zhuang, C. Meng, X. Guo et al., "A novel regulator of macrophage activation: MiR-223 in obesity-associated adipose tissue inflammation," Circulation, vol. 125, no. 23, pp. 2892-2903, 2012.

[102] G. Boden, P. Cheung, K. Kresge, C. Homko, B. Powers, and L. Ferrer, "Insulin resistance is associated with diminished endoplasmic reticulum stress responses in adipose tissue of healthy and diabetic subjects," Diabetes, vol. 63, no. 9, pp. 2977-2983, 2014.

[103] W. Ying, M. Riopel, G. Bandyopadhyay et al., "Adipose tissue macrophage-derived exosomal miRNAs can modulate in vivo and in vitro insulin sensitivity," Cell, vol. 171, no. 2, pp. 372384.e12, 2017.

[104] P. Tontonoz and B. M. Spiegelman, "Fat and beyond: the diverse biology of PPAR $\gamma$," Annual Review of Biochemistry, vol. 77, no. 1, pp. 289-312, 2008.

[105] Z. B. Deng, A. Poliakov, R. W. Hardy et al., "Adipose tissue exosome-like vesicles mediate activation of macrophageinduced insulin resistance," Diabetes, vol. 58, no. 11, pp. 2498-2505, 2009.

[106] M. E. Kranendonk, F. L. Visseren, J. A. van Herwaarden et al., "Effect of extracellular vesicles of human adipose tissue on insulin signaling in liver and muscle cells," Obesity, vol. 22, no. 10 , pp. 2216-2223, 2014.

[107] S. C. Ferrante, E. P. Nadler, D. K. Pillai et al., "Adipocyte-derived exosomal miRNAs: a novel mechanism for obesity-related disease," Pediatric Research, vol. 77, no. 3, pp. 447-454, 2015. 
[108] D. S. Karolina, S. Tavintharan, A. Armugam et al., "Circulating miRNA profiles in patients with metabolic syndrome," The Journal of Clinical Endocrinology \& Metabolism, vol. 97, no. 12, pp. E2271-E2276, 2012.

[109] T. Thomou, M. A. Mori, J. M. Dreyfuss et al., "Adiposederived circulating miRNAs regulate gene expression in other tissues," Nature, vol. 542, no. 7642, pp. 450-455, 2017.

[110] M. J. Potthoff, T. Inagaki, S. Satapati et al., "FGF21 induces PGC- $1 \alpha$ and regulates carbohydrate and fatty acid metabolism during the adaptive starvation response," Proceedings of the National Academy of Sciences of the United States of America, vol. 106, no. 26, pp. 1085310858, 2009.

[111] T. Lopatina, S. Bruno, C. Tetta, N. Kalinina, M. Porta, and G. Camussi, "Platelet-derived growth factor regulates the secretion of extracellular vesicles by adipose mesenchymal stem cells and enhances their angiogenic potential," Cell Communication and Signaling, vol. 12, no. 1, p. 26, 2014.

[112] G. Togliatto, P. Dentelli, M. Gili et al., "Obesity reduces the pro-angiogenic potential of adipose tissue stem cell-derived extracellular vesicles (EVs) by impairing miR-126 content: impact on clinical applications," International Journal of Obesity, vol. 40, no. 1, pp. 102-111, 2016.

[113] C. Hewson, D. Capraro, J. Burdach, N. Whitaker, and K. V. Morris, "Extracellular vesicle associated long non-coding RNAs functionally enhance cell viability," Non-coding RNA Research, vol. 1, no. 1, pp. 3-11, 2016.

[114] X. Ruan, "Long non-coding RNA central of glucose homeostasis," Journal of Cellular Biochemistry, vol. 117, no. 5, pp. 1061-1065, 2016.

[115] S. Wei, M. Du, Z. Jiang, G. J. Hausman, L. Zhang, and M. V. Dodson, "Long noncoding RNAs in regulating adipogenesis: new RNAs shed lights on obesity," Cellular and Molecular Life Sciences, vol. 73, no. 10, pp. 2079-2087, 2016.

[116] M. Asrih and F. R. Jornayvaz, "Metabolic syndrome and nonalcoholic fatty liver disease: is insulin resistance the link?," Molecular and Cellular Endocrinology, vol. 418, Part 1, pp. 55-65, 2015.

[117] D. García-Compeán, J. A. González-González, F. J. LavalleGonzález, E. I. González-Moreno, H. J. Maldonado-Garza, and J. Z. Villarreal-Pérez, "The treatment of diabetes mellitus of patients with chronic liver disease," Annals of Hepatology, vol. 14, no. 6, pp. 780-788, 2015.

[118] I. Huang-Doran, C.-Y. Zhang, and A. Vidal-Puig, "Extracellular vesicles: novel mediators of cell communication in metabolic disease," Trends in Endocrinology \& Metabolism, vol. 28, no. 1, pp. 3-18, 2017.

[119] F. Royo and J. M. Falcon-Perez, "Liver extracellular vesicles in health and disease," Journal of Extracellular Vesicles, vol. 1, no. 1, article 18825, 2012.

[120] J. Shen, C. K. Huang, H. Yu et al., "The role of exosomes in hepatitis, liver cirrhosis and hepatocellular carcinoma," Journal of Cellular and Molecular Medicine, vol. 21, no. 5, pp. 986-992, 2017.

[121] P. Angulo, D. E. Kleiner, S. Dam-Larsen et al., "Liver fibrosis, but no other histologic features, is associated with long-term outcomes of patients with nonalcoholic fatty liver disease," Gastroenterology, vol. 149, no. 2, pp. 389-397.e10, 2015.

[122] P. Angulo, "Nonalcoholic fatty liver disease," The New England Journal of Medicine, vol. 346, no. 16, pp. 12211231, 2002.
[123] M. Kornek, M. Lynch, S. H. Mehta et al., "Circulating microparticles as disease-specific biomarkers of severity of inflammation in patients with hepatitis $\mathrm{C}$ or nonalcoholic steatohepatitis," Gastroenterology, vol. 143, no. 2, pp. 448458, 2012.

[124] D. Povero, A. Eguchi, I. R. Niesman et al., "Lipid-induced toxicity stimulates hepatocytes to release angiogenic microparticles that require Vanin-1 for uptake by endothelial cells," Science Signaling, vol. 6, no. 296, article ra88, 2013.

[125] D. Povero, A. Eguchi, H. Li et al., "Circulating extracellular vesicles with specific proteome and liver microRNAs are potential biomarkers for liver injury in experimental fatty liver disease," PLoS One, vol. 9, no. 12, article e113651, 2014.

[126] P. Hirsova, S. H. Ibrahim, A. Krishnan et al., "Lipid-induced signaling causes release of inflammatory extracellular vesicles from hepatocytes," Gastroenterology, vol. 150, no. 4, pp. 956967, 2016.

[127] E. S. Koeck, T. Iordanskaia, S. Sevilla et al., "Adipocyte exosomes induce transforming growth factor beta pathway dysregulation in hepatocytes: a novel paradigm for obesityrelated liver disease," The Journal of Surgical Research, vol. 192, no. 2, pp. 268-275, 2014.

[128] M. Osmai, Y. Osmai, C. H. Bang-Berthelsen et al., "MicroRNAs as regulators of beta-cell function and dysfunction," Diabetes/Metabolism Research and Reviews, vol. 32, no. 4, pp. 334-349, 2016.

[129] C. Guay, V. Menoud, S. Rome, and R. Regazzi, "Horizontal transfer of exosomal microRNAs transduce apoptotic signals between pancreatic beta-cells," Cell Communication and Signaling, vol. 13, no. 1, p. 17, 2015.

[130] S. Narayanan, G. Loganathan, M. Dhanasekaran et al., "Intraislet endothelial cell and $\beta$-cell crosstalk: implication for islet cell transplantation," World Journal of Transplantation, vol. 7, no. 2, pp. 117-128, 2017.

[131] F. Figliolini, V. Cantaluppi, M. De Lena et al., "Isolation, characterization and potential role in beta cell-endothelium cross-talk of extracellular vesicles released from human pancreatic islets," PLoS One, vol. 9, no. 7, article e102521, 2014.

[132] V. Cantaluppi, L. Biancone, F. Figliolini et al., "Microvesicles derived from endothelial progenitor cells enhance neoangiogenesis of human pancreatic islets," Cell Transplantation, vol. 21, no. 6, pp. 1305-1320, 2012.

[133] G. Ventriglia, L. Nigi, G. Sebastiani, and F. Dotta, "MicroRNAs: novel players in the dialogue between pancreatic islets and immune system in autoimmune diabetes," BioMed Research International, vol. 2015, Article ID 749734, 11 pages, 2015.

[134] C. Cianciaruso, E. A. Phelps, M. Pasquier et al., "Primary human and rat $\beta$-cells release the intracellular autoantigens GAD65, IA-2, and proinsulin in exosomes together with cytokine-induced enhancers of immunity," Diabetes, vol. 66, no. 2, pp. 460-473, 2017.

[135] F. C. Lynn, P. Skewes-Cox, Y. Kosaka, M. T. McManus, B. D. Harfe, and M. S. German, "MicroRNA expression is required for pancreatic islet cell genesis in the mouse," Diabetes, vol. 56, no. 12, pp. 2938-2945, 2007.

[136] H. Chen, H. Y. Lan, D. H. Roukos, and W. C. Cho, "Application of microRNAs in diabetes mellitus," The Journal of Endocrinology, vol. 222, no. 1, pp. R1-R10, 2014.

[137] H. A. Malm, I. G. Mollet, C. Berggreen et al., “Transcriptional regulation of the miR-212/miR-132 cluster in insulin- 
secreting $\beta$-cells by cAMP-regulated transcriptional coactivator 1 and salt-inducible kinases," Molecular and Cellular Endocrinology, vol. 424, pp. 23-33, 2016.

[138] M. S. Soni, M. E. Rabaglia, S. Bhatnagar et al., "Downregulation of carnitine acyl-carnitine translocase by miRNAs 132 and 212 amplifies glucose-stimulated insulin secretion," Diabetes, vol. 63, no. 11, pp. 3805-3814, 2014.

[139] C. Jacovetti, A. Abderrahmani, G. Parnaud et al., "MicroRNAs contribute to compensatory $\beta$ cell expansion during pregnancy and obesity," The Journal of Clinical Investigation, vol. 122, no. 10, pp. 3541-3551, 2012.

[140] C. Jacovetti, V. Jimenez, E. Ayuso et al., "Contribution of Intronic miR-338-3p and its hosting gene AATK to compensatory $\beta$-cell mass expansion," Molecular Endocrinology, vol. 29, no. 5, pp. 693-702, 2015.

[141] M. N. Poy, J. Hausser, M. Trajkovski et al., " $m i R-375$ maintains normal pancreatic $\alpha$ - and $\beta$-cell mass," Proceedings of the National Academy of Sciences of the United States of America, vol. 106, no. 14, pp. 5813-5818, 2009.

[142] M. N. Poy, L. Eliasson, J. Krutzfeldt et al., "A pancreatic islet-specific microRNA regulates insulin secretion," Nature, vol. 432, no. 7014, pp. 226-230, 2004.

[143] A. Jalabert, G. Vial, C. Guay et al., "Exosome-like vesicles released from lipid-induced insulin-resistant muscles modulate gene expression and proliferation of beta recipient cells in mice," Diabetologia, vol. 59, no. 5, pp. 1049-1058, 2016.

[144] Y. Dou, D. J. Cha, J. L. Franklin et al., "Circular RNAs are down-regulated in KRAS mutant colon cancer cells and can be transferred to exosomes," Scientific Reports, vol. 6, no. 1, 2016.

[145] Y. Li, Q. Zheng, C. Bao et al., "Circular RNA is enriched and stable in exosomes: a promising biomarker for cancer diagnosis," Cell Research, vol. 25, no. 8, pp. 981-984, 2015.

[146] E. Lasda and R. Parker, "Circular RNAs co-precipitate with extracellular vesicles: a possible mechanism for circRNA clearance," PLoS One, vol. 11, no. 2, article e0148407, 2016.

[147] T. B. Hansen, T. I. Jensen, B. H. Clausen et al., "Natural RNA circles function as efficient microRNA sponges," Nature, vol. 495, no. 7441, pp. 384-388, 2013.

[148] H. Xu, S. Guo, W. Li, and P. Yu, "The circular RNA Cdrlas, via miR-7 and its targets, regulates insulin transcription and secretion in islet cells," Scientific Reports, vol. 5, no. 1, 2015.

[149] M. Latreille, J. Hausser, I. Stützer et al., "MicroRNA-7a regulates pancreatic $\beta$ cell function," The Journal of Clinical Investigation, vol. 124, no. 6, pp. 2722-2735, 2014.

[150] G. Sebastiani, L. Nigi, G. E. Grieco, F. Mancarella, G. Ventriglia, and F. Dotta, "Circulating microRNAs and diabetes mellitus: a novel tool for disease prediction, diagnosis, and staging?," Journal of Endocrinological Investigation, vol. 40, no. 6, pp. 591-610, 2017.

[151] M. Garcia-Contreras, S. H. Shah, A. Tamayo et al., "Plasmaderived exosome characterization reveals a distinct microRNA signature in long duration type 1 diabetes," Scientific Reports, vol. 7, no. 1, article 5998, 2017.

[152] F. Barutta, M. Tricarico, A. Corbelli et al., "Urinary exosomal microRNAs in incipient diabetic nephropathy," PLoS One, vol. 8, no. 11, article e73798, 2013.

[153] P. Vallabhajosyula, L. Korutla, A. Habertheuer et al., "Tissuespecific exosome biomarkers for noninvasively monitoring immunologic rejection of transplanted tissue," The Journal of Clinical Investigation, vol. 127, no. 4, pp. 1375-1391, 2017.
[154] D. Wen, Y. Peng, D. Liu, Y. Weizmann, and R. I. Mahato, "Mesenchymal stem cell and derived exosome as small RNA carrier and immunomodulator to improve islet transplantation," Journal of Controlled Release, vol. 238, pp. 166175, 2016.

[155] E. Favaro, A. Carpanetto, S. Lamorte et al., "Human mesenchymal stem cell-derived microvesicles modulate $\mathrm{T}$ cell response to islet antigen glutamic acid decarboxylase in patients with type 1 diabetes," Diabetologia, vol. 57, no. 8 , pp. 1664-1673, 2014.

[156] E. Favaro, A. Carpanetto, C. Caorsi et al., "Human mesenchymal stem cells and derived extracellular vesicles induce regulatory dendritic cells in type 1 diabetic patients," Diabetologia, vol. 59, no. 2, pp. 325-333, 2016.

[157] R. Ross, "Atherosclerosis-an inflammatory disease," The New England Journal of Medicine, vol. 340, no. 2, pp. 115126, 1999.

[158] B. Gustafson, "Adipose tissue, inflammation and atherosclerosis," Journal of Atherosclerosis and Thrombosis, vol. 17, no. 4, pp. 332-341, 2010.

[159] X. Sun, A. Sit, and M. W. Feinberg, "Role of miR-181 family in regulating vascular inflammation and immunity," Trends in Cardiovascular Medicine, vol. 24, no. 3, pp. 105-112, 2014.

[160] A. D'avalos, L. Goedeke, P. Smibert et al., “miR-33a/b contribute to the regulation of fatty acid metabolism and insulin signaling," Proceedings of the National Academy of Sciences of the United States of America, vol. 108, no. 22, pp. 9232-9237, 2011.

[161] C. M. Ramirez, L. Goedeke, N. Rotllan et al., "MicroRNA 33 regulates glucose metabolism," Molecular and Cellular Biology, vol. 33, no. 15, pp. 2891-2902, 2013.

[162] M. Shirasaki, T. Honda, T. Shimakami et al., "MicroRNA-27a regulates lipid metabolism and inhibits hepatitis $\mathrm{C}$ virus replication in human hepatoma cells," Journal of Virology, vol. 87, no. 9, pp. 5270-5286, 2013.

[163] K. C. Vickers, B. M. Shoucri, M. G. Levin et al., "MicroRNA$27 \mathrm{~b}$ is a regulatory hub in lipid metabolism and is altered in dyslipidemia," Hepatology, vol. 57, no. 2, pp. 533-542, 2013.

[164] C. Esau, S. Davis, S. F. Murray et al., "miR-122 regulation of lipid metabolism revealed by in vivo antisense targeting," Cell Metabolism, vol. 3, no. 2, pp. 87-98, 2006.

[165] S. Kumar, C. W. Kim, R. D. Simmons, and H. Jo, "Role of flow-sensitive microRNAs in endothelial dysfunction and atherosclerosis: mechanosensitive athero-miRs," Arteriosclerosis, Thrombosis, and Vascular Biology, vol. 34, no. 10, pp. 2206-2216, 2014.

[166] E. Hergenreider, S. Heydt, K. Tréguer et al., “Atheroprotective communication between endothelial cells and smooth muscle cells through miRNAs," Nature Cell Biology, vol. 14, no. 3, pp. 249-256, 2012.

[167] M. Climent, M. Quintavalle, M. Miragoli, J. Chen, G. Condorelli, and L. Elia, "TGF $\beta$ triggers miR-143/145 transfer from smooth muscle cells to endothelial cells, thereby modulating vessel stabilization," Circulation Research, vol. 116, no. 11, pp. 1753-1764, 2015.

[168] B. Zheng, W. N. Yin, T. Suzuki et al., "Exosome-mediated miR-155 transfer from smooth muscle cells to endothelial cells induces endothelial injury and promotes atherosclerosis," Molecular Therapy, vol. 25, no. 6, pp. 1279-1294, 2017.

[169] D. de Gonzalo-Calvo, A. Cenarro, K. Garlaschelli et al., "Translating the microRNA signature of microvesicles 
derived from human coronary artery smooth muscle cells in patients with familial hypercholesterolemia and coronary artery disease," Journal of Molecular and Cellular Cardiology, vol. 106, pp. 55-67, 2017.

[170] D. Kirsten, "The thyroid gland: physiology and pathophysiology," Neonatal Network, vol. 19, no. 8, pp. 11-26, 2000.

[171] K. Agarwal, M. Saji, S. M. Lazaroff, A. F. Palmer, M. D. Ringel, and M. E. Paulaitis, "Analysis of exosome release as a cellular response to MAPK pathway inhibition," Langmuir, vol. 31, no. 19, pp. 5440-5448, 2015.

[172] J. Ochieng, S. Pratap, A. K. Khatua, and A. M. Sakwe, "Anchorage-independent growth of breast carcinoma cells is mediated by serum exosomes," Experimental Cell Research, vol. 315, no. 11, pp. 1875-1888, 2009.

[173] A. E. Berezin, A. A. Kremzer, Y. V. Martovitskaya, T. A. Samura, and T. A. Berezina, "Pattern of circulating endothelial-derived microparticles among chronic heart failure patients with dysmetabolic comorbidities: the impact of subclinical hypothyroidism," Diabetes \& Metabolic Syndrome: Clinical Research \& Reviews, vol. 10, no. 1, pp. 2936, 2016.

[174] S. M. Ferrari, P. Fallahi, A. Antonelli, and S. Benvenga, "Environmental issues in thyroid diseases," Frontiers in Endocrinology, vol. 8, p. 50, 2017.

[175] J. Burrello, S. Monticone, C. Gai, Y. Gomez, S. Kholia, and G. Camussi, "Stem cell-derived extracellular vesicles and immune-modulation," Frontiers in Cell and Development Biology, vol. 4, p. 83, 2016.

[176] B. Wang, X. Shao, R. Song, D. Xu, and J. A. Zhang, "The emerging role of epigenetics in autoimmune thyroid diseases," Frontiers in Immunology, vol. 8, p. 396, 2017.

[177] F. Mobarrez, M. Abraham-Nordling, K. Aguilera-Gatica et al., "The expression of microvesicles in the blood of patients with Graves' disease and its relationship to treatment," Clinical Endocrinology, vol. 84, no. 5, pp. 729735, 2016.

[178] A. Rodriguez-Munoz, R. Martinez-Hernandez, A. M. RamosLeví et al., "Circulating microvesicles regulate Treg and Th17 differentiation in human autoimmune thyroid disorders," The Journal of Clinical Endocrinology \& Metabolism, vol. 100, no. 12, pp. E1531-E1539, 2015.

[179] N. J. Christensen, G. Habekost, and P. Bratholm, “A RNA transcript (Heg) in mononuclear cells is negatively correlated with CD14 mRNA and TSH receptor autoantibodies," Clinical and Experimental Immunology, vol. 154, no. 2, pp. 209-215, 2008.

[180] R. M. O’Connell, D. S. Rao, A. A. Chaudhuri, and D. Baltimore, "Physiological and pathological roles for microRNAs in the immune system," Nature Reviews Immunology, vol. 10, no. 2, pp. 111-122, 2010.

[181] H. Peng, Y. Liu, J. Tian et al., "The long noncoding RNA IFNG-AS1 promotes Thelper type 1 cells response in patients with Hashimoto's thyroiditis," Scientific Reports, vol. 5, no. 1, 2015.

[182] I. Hiratsuka, H. Yamada, E. Munetsuna, S. Hashimoto, and M. Itoh, "Circulating MicroRNAs in Graves' disease in relation to clinical activity," Thyroid, vol. 26, no. 10, pp. 1431-1440, 2016.

[183] X. Huang, T. Yuan, M. Tschannen et al., "Characterization of human plasma-derived exosomal RNAs by deep sequencing," BMC Genomics, vol. 14, no. 1, p. 319, 2013.
[184] A. Lakshmanan, A. Wojcicka, M. Kotlarek, X. Zhang, K. Jazdzewski, and S. M. Jhiang, "microRNA-339-5p modulates $\mathrm{Na}^{+} / \mathrm{I}^{-}$symporter-mediated radioiodide uptake," Endocrine Related Cancer, vol. 22, no. 1, pp. 11-21, 2015.

[185] C. Portulano, M. Paroder-Belenitsky, and N. Carrasco, "The $\mathrm{Na}^{+} / \mathrm{I}^{-}$symporter (NIS): mechanism and medical impact," Endocrine Reviews, vol. 35, no. 1, pp. 106-149, 2014.

[186] M. D. Mitchell, H. N. Peiris, M. Kobayashi et al., "Placental exosomes in normal and complicated pregnancy," American Journal of Obstetrics and Gynecology, vol. 213, no. 4, pp. S173-S181, 2015.

[187] R. Machtinger, L. C. Laurent, and A. A. Baccarelli, "Extracellular vesicles: roles in gamete maturation, fertilization and embryo implantation," Human Reproduction Update, vol. 22, no. 2, pp. 182-193, 2016.

[188] C. Salomon, S. W. Yee, M. D. Mitchell, and G. E. Rice, “The possible role of extravillous trophoblast-derived exosomes on the uterine spiral arterial remodeling under both normal and pathological conditions," BioMed Research International, vol. 2014, Article ID 693157, 10 pages, 2014.

[189] C. Salomon, M. J. Torres, and M. Kobayashi, “A gestational profile of placental exosomes in maternal plasma and their effects on endothelial cell migration," PLoS One, vol. 9, no. 6, article e98667, 2014.

[190] P. Pillay, N. Maharaj, J. Moodley, and I. Mackraj, "Placental exosomes and pre-eclampsia: maternal circulating levels in normal pregnancies and, early and late onset pre-eclamptic pregnancies," Placenta, vol. 46, pp. 18-25, 2016.

[191] C. Salomon, K. Scholz-Romero, S. Sarker et al., "Gestational diabetes mellitus is associated with changes in the concentration and bioactivity of placenta-derived exosomes in maternal circulation across gestation," Diabetes, vol. 65, no. 3, pp. 598-609, 2016.

[192] D. Tannetta, I. Masliukaite, M. Vatish, C. Redman, and I. Sargent, "Update of syncytiotrophoblast derived extracellular vesicles in normal pregnancy and preeclampsia," Journal of Reproductive Immunology, vol. 119, pp. 98-106, 2017.

[193] C. Salomon, M. Kobayashi, K. Ashman, L. Sobrevia, M. D. Mitchell, and G. E. Rice, "Hypoxia-induced changes in the bioactivity of cytotrophoblast-derived exosomes," PLoS One, vol. 8, article e79636, no. 11, 2013.

[194] C. Salomon, J. Ryan, L. Sobrevia et al., "Exosomal signaling during hypoxia mediates microvascular endothelial cell migration and vasculogenesis," PLoS One, vol. 8, no. 7, article e68451, 2013.

[195] L. K. Harris, "IFPA Gabor than award lecture: transformation of the spiral arteries in human pregnancy: key events in the remodelling timeline," Placenta, vol. 32, pp. S154-S158, 2011.

[196] E. Delorme-Axford, R. B. Donker, J. F. Mouillet et al., "Human placental trophoblasts confer viral resistance to recipient cells," Proceedings of the National Academy of Sciences of the United States of America, vol. 110, no. 29, pp. 12048-12053, 2013.

[197] A. Bayer, E. Delorme-Axford, C. Sleigher et al., "Human trophoblasts confer resistance to viruses implicated in perinatal infection," American Journal of Obstetrics and Gynecology, vol. 212, no. 1, pp. 71.e1-71.e8, 2015.

[198] K. R. Bounds, V. L. Chiasson, L. J. Pan, S. Gupta, and P. Chatterjee, "MicroRNAs: new players in the pathobiology of preeclampsia," Frontiers in Cardiovascular Medicine, vol. 4 , p. $60,2017$. 
[199] A. Boutin, C. Gasse, S. Demers, Y. Giguère, A. Tétu, and E. Bujold, "Maternal characteristics for the prediction of preeclampsia in nulliparous women: the great obstetrical syndromes (GOS) study," Journal of Obstetrics and Gynaecology Canada, 2017.

[200] S. I. Gilani, T. L. Weissgerber, V. D. Garovic, and M. Jayachandran, "Preeclampsia and extracellular vesicles," Current Hypertension Reports, vol. 18, no. 9, p. 68, 2016.

[201] C. A. Escudero, K. Herlitz, F. Troncoso et al., "Role of extracellular vesicles and microRNAs on dysfunctional angiogenesis during preeclamptic pregnancies," Frontiers in Physiology, vol. 7, pp. 98-114, 2017.

[202] J. S. M. Cuffe, O. Holland, C. Salomon, G. E. Rice, and A. V. Perkins, "Review: placental derived biomarkers of pregnancy disorders," Placenta, vol. 54, pp. 104-110, 2017.

[203] I. M. Saadeldin, M. Islam, H. J. Oh, and B. C. Lee, "Embryonic-maternal cross-talk via exosomes: potential implications," Stem Cells and Cloning: Advances and Applications, vol. 8, pp. 103-107, 2015.

[204] S. Atay, C. Gercel-Taylor, J. Suttles, G. Mor, and D. D. Taylor, "Trophoblast-derived exosomes mediate monocyte recruitment and differentiation," American Journal of Reproductive Immunology, vol. 65, no. 1, pp. 65-77, 2011.

[205] M. Familari, T. Cronqvist, Z. Masoumi, and S. R. Hansson, "Placenta-derived extracellular vesicles: their cargo and possible functions," Reproduction, Fertility, and Development, vol. 29, no. 3, pp. 433-447, 2015.

[206] W. Kam, E. Clauser, Y. S. Kim, Y. W. Kan, and W. J. Rutter, "Cloning, sequencing, and chromosomal localization of human term placental alkaline phosphatase cDNA," Proceedings of the National Academy of Sciences of the United States of America, vol. 82, no. 24, pp. 8715-8719, 1985.

[207] Z. Yuan, X. Sun, D. Jiang et al., "Origin and evolution of a placental-specific microRNA family in the human genome," BMC Evolutionary Biology, vol. 10, no. 1, p. 346, 2010.

[208] S. Kambe, H. Yoshitake, K. Yuge et al., "Human exosomal placenta-associated $m i R-517 \alpha-3 p$ modulates the expression of PRKG1 mRNA in Jurkat cells," Biology of Reproduction, vol. 91, no. 5, p. 129, 2014.

[209] D. Y. Xiao, J. Ohlendorf, Y. L. Chen et al., "Identifying mRNA, MicroRNA and protein profiles of melanoma exosomes," PLoS One, vol. 7, no. 10, article e46874, 2012.

[210] G. Rabinowits, C. Gerçel-Taylor, J. M. Day, D. D. Taylor, and G. H. Kloecker, "Exosomal microRNA: a diagnostic marker for lung cancer," Clinical Lung Cancer, vol. 10, no. 1, pp. 42-46, 2009.

[211] D. Goswami, D. S. Tannetta, L. A. Magee et al., "Excess syncytiotrophoblast microparticle shedding is a feature of early-onset pre-eclampsia, but not normotensive intrauterine growth restriction," Placenta, vol. 27, no. 1, pp. 56-61, 2006.

[212] C. Salomon, K. Scholz-Romero, M. Kobayashi et al., "Oxygen tension regulates glucose-induced biogenesis and release of different subpopulations of exosome vesicles from trophoblast cells: a gestational age profile of placental exosomes in maternal plasma with gestational diabetes mellitus," Placenta, vol. 36, no. 4, p. 488, 2015.

[213] J. E. Cartwright, R. J. Keogh, and M. C. Tissot van Patot, "Hypoxia and placental remodelling," in Hypoxia and the Circulation, R. C. Roach, P. D. Wagner, and P. H. Hackett, Eds., vol. 618 of Adv Exp Med Biol, pp. 113-126, Springer, Boston, MA, USA, 2007.
[214] G. Truong, D. Guanzon, V. Kinhal et al., "Oxygen tension regulates the miRNA profile and bioactivity of exosomes released from extravillous trophoblast cells - liquid biopsies for monitoring complications of pregnancy," PLoS One, vol. 12, no. 3, article e0174514, 2017.

[215] R. B. Donker, J. F. Mouillet, T. Chu et al., "The expression profile of C19MC microRNAs in primary human trophoblast cells and exosomes," Molecular Human Reproduction, vol. 18, no. 8, pp. 417-424, 2012.

[216] C. Salomon, D. Guanzon, K. Scholz-Romero et al., "Placental exosomes as early biomarker of preeclampsia: potential role of exosomal microRNAs across gestation," The Journal of Clinical Endocrinology \& Metabolism, vol. 102, no. 9, pp. 3182-3194, 2017.

[217] P. Vlasov, S. Q. Doi, and D. F. Sellitti, "FRTL-5 rat thyroid cells release thyroglobulin sequestered in exosomes: a possible novel mechanism for thyroglobulin processing in the thyroid," Journal of Thyroid Research, vol. 2016, Article ID 9276402, 7 pages, 2016.

[218] X. Wang, W. Huang, G. Liu et al., "Cardiomyocytes mediate anti-angiogenesis in type 2 diabetic rats through the exosomal transfer of miR-320 into endothelial cells," Journal of Molecular and Cellular Cardiology, vol. 74, pp. 139150, 2014.

[219] A. Kalani, P. Chaturvedi, C. Maldonado et al., "Dementia-like pathology in type-2 diabetes: a novel microRNA mechanism," Molecular and Cellular Neurosciences, vol. 80, pp. 58-65, 2017. 


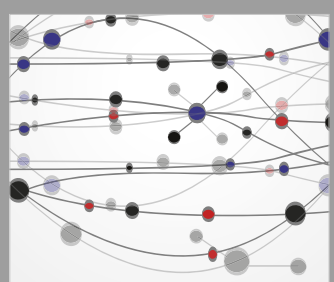

The Scientific World Journal
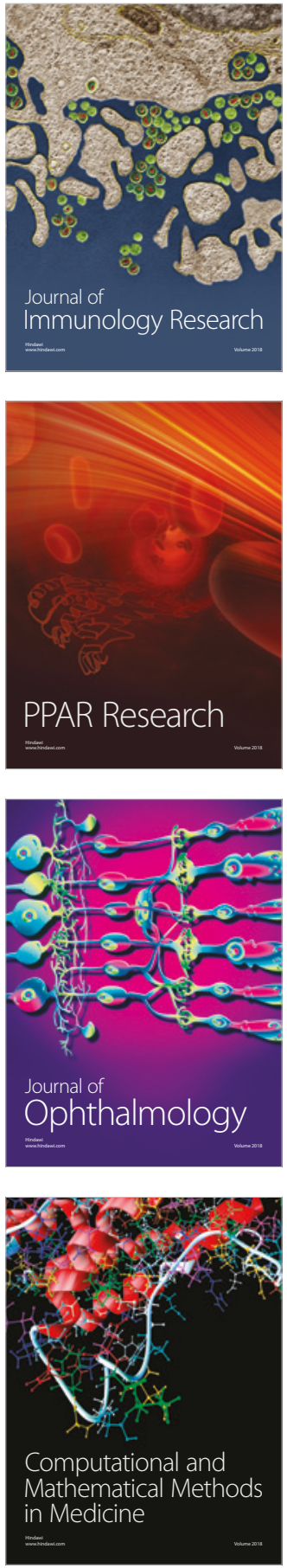

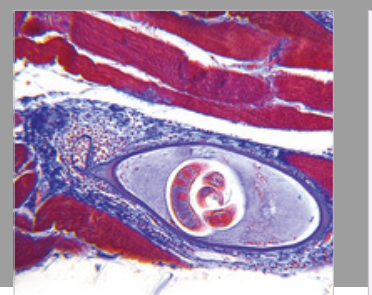

Gastroenterology Research and Practice

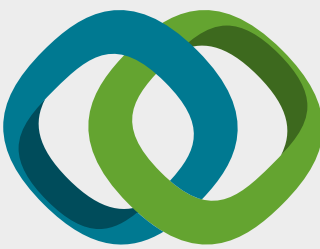

\section{Hindawi}

Submit your manuscripts at

www.hindawi.com
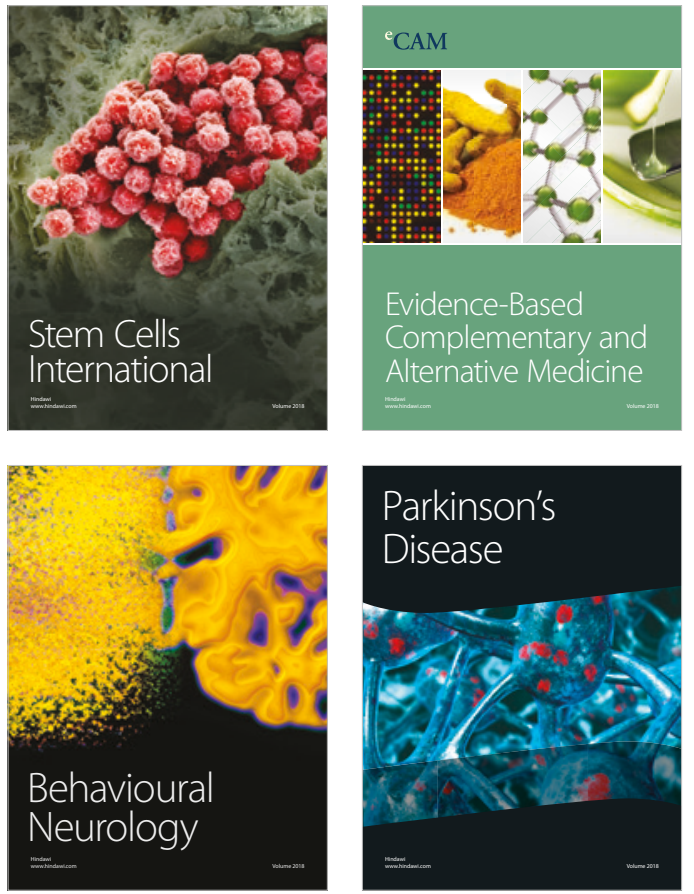

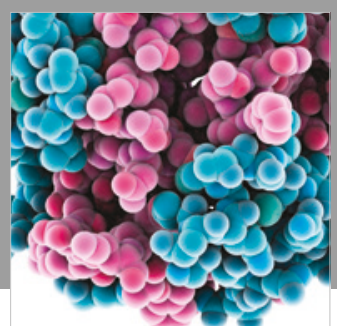

ournal of

Diabetes Research

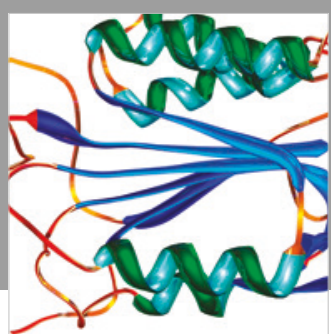

Disease Markers
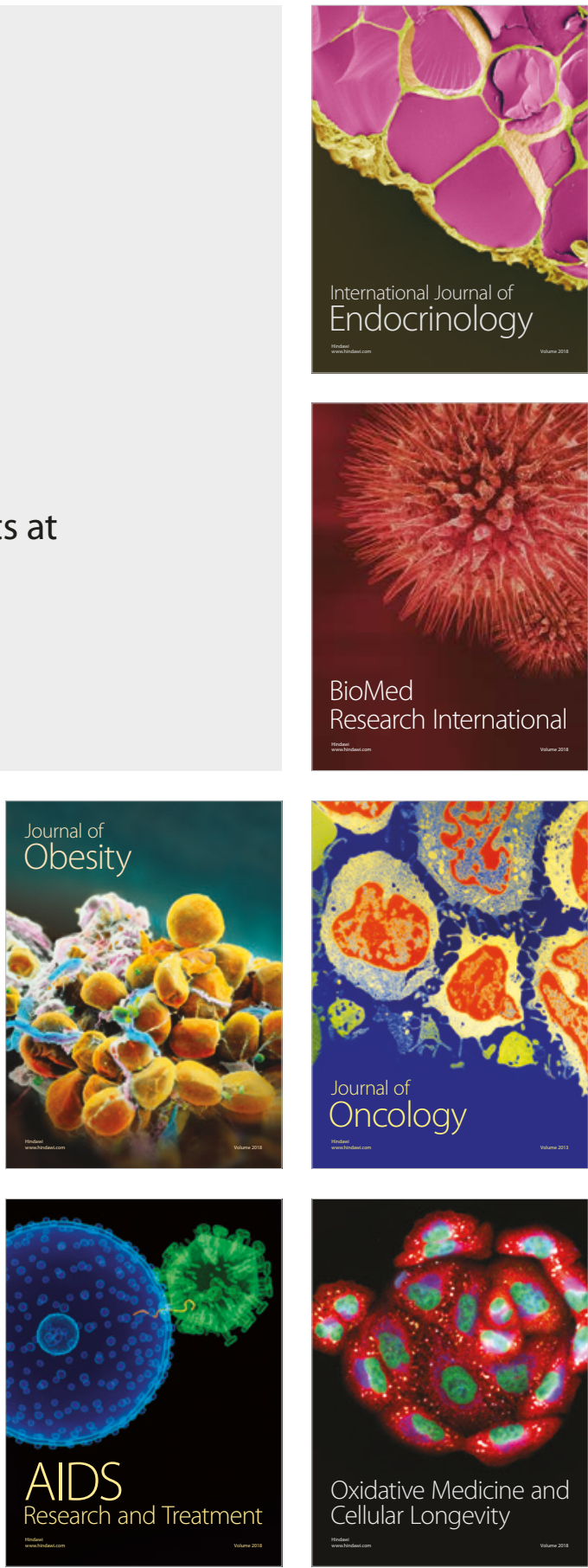